\title{
The Impact of Cortical Deafferentation on the Neocortical Slow Oscillation
}

\author{
Maxime Lemieux, ${ }^{1}$ Jen-Yung Chen, ${ }^{2}$ Peter Lonjers, ${ }^{2}$ Maxim Bazhenov, ${ }^{2}$ and Igor Timofeev ${ }^{1,3}$ \\ ${ }^{1}$ Centre de recherche de l'Institut Universitaire en Santé Mentale de Québec, Université Laval, Québec G1J 2G3, Canada, ${ }^{2}$ Department of Cell Biology and \\ Neuroscience, University of California, Riverside, California 92521, and 3 Department of Psychiatry and Neuroscience, Université Laval, Québec G1V 0A6, \\ Canada
}

\begin{abstract}
Slow oscillation is the main brain rhythm observed during deep sleep in mammals. Although several studies have demonstrated its neocortical origin, the extent of the thalamic contribution is still a matter of discussion. Using electrophysiological recordings in vivo on cats and computational modeling, we found that the local thalamic inactivation or the complete isolation of the neocortical slabs maintained within the brain dramatically reduced the expression of slow and fast oscillations in affected cortical areas. The slow oscillation began to recover $12 \mathrm{~h}$ after thalamic inactivation. The slow oscillation, but not faster activities, nearly recovered after $30 \mathrm{~h}$ and persisted for weeks in the isolated slabs. We also observed an increase of the membrane potential fluctuations recorded in vivo several hours after thalamic inactivation. Mimicking this enhancement in a network computational model with an increased postsynaptic activity of long-range intracortical afferents or scaling $\mathrm{K}^{+}$leak current, but not several other $\mathrm{Na}^{+}$and $\mathrm{K}^{+}$intrinsic currents was sufficient for recovering the slow oscillation. We conclude that, in the intact brain, the thalamus contributes to the generation of cortical active states of the slow oscillation and mediates its large-scale synchronization. Our study also suggests that the deafferentation-induced alterations of the sleep slow oscillation can be counteracted by compensatory intracortical mechanisms and that the sleep slow oscillation is a fundamental and intrinsic state of the neocortex.
\end{abstract}

Key words: cortex; in vivo; model; plasticity; slow oscillation; thalamus

\section{Introduction}

Sleep occupies approximately one-third to one-half of each day in the majority of mammalian species (Siegel, 2005). Thalamocortical activities during deep sleep are dominated by a slow oscillation $(<1 \mathrm{~Hz}$; Blake and Gerard, 1937) that appears as an alternation of active (UP) and silent (DOWN) states of cortical neurons (Steriade et al., 1993b; Steriade et al., 2001; Timofeev et al., 2001). This synchronous neuronal activity generates the EEG slow waves (Contreras and Steriade, 1995; Chauvette et al., 2010). The slow-wave sleep is essential for memory formation and consolidation (Gais et al., 2000; Stickgold et al., 2000; Maquet, 2001; Huber et al., 2004; Marshall et al., 2006) and it has been proposed that synaptic plasticity associated with different brain rhythms contributes to memory consolidation (Timofeev et al., 2000; Steriade and Timofeev, 2003; Tononi and Cirelli, 2006; Diekelmann

Received March 17, 2013; revised March 6, 2014; accepted March 11, 2014.

Author contributions: M.L., M.B., and I.T. designed research; M.L., J.-Y.C., P.L., and I.T. performed research; M.L., J.-Y.C., P.L., and I.T. analyzed data; M.L., M.B., and I.T. wrote the paper.

This work was supported by Canadian Institutes of Health Research, National Institute of Neurological Disorders and Stroke, National Institute of Biomedical Imaging and Bioengineering, National Institute of Mental Health, Office of Naval Research-Multidisciplinary University Research Initiative, National Science Engineering Research Council and Fonds de recherche du Québec-Santé. We are thankful to Serge Ftomov for the technical assistance and Josée Seigneur for management assistance.

The authors declare no competing financial interests.

Correspondence should be addressed to Igor Timofeev, Centre de recherche de l'Institut Universitaire en Santé Mentale de Québec (CRIUSMQ), Université Laval, Québec G1J 2G3, Canada. E-mail: igor.timofeev@phs.ulaval.ca.

DOI:10.1523/JNEUROSCI.1156-13.2014

Copyright $\odot 2014$ the authors $\quad 0270-6474 / 14 / 345689-15 \$ 15.00 / 0$ and Born, 2010; Timofeev, 2011; Vyazovskiy et al., 2011; Chauvette et al., 2012).

Despite recent progress, the role and mechanisms of sleep (Steriade et al., 1993c; Destexhe and Sejnowski, 2001; Maquet, 2001; Steriade and Timofeev, 2003; Tononi and Cirelli, 2006; Diekelmann and Born, 2010) and the origin of the synchronous sleep slow oscillation remains a controversial topic. A number of studies (Timofeev and Steriade, 1996; SanchezVives and McCormick, 2000; Timofeev et al., 2000; Bazhenov et al., 2002; Shu et al., 2003; Hasenstaub et al., 2005; MacLean et al., 2005; Rudolph et al., 2007; Csercsa et al., 2010) have suggested that the neocortex is, in itself, sufficient to generate the slow activity characteristic of slow-wave sleep via recurrent excitatory and inhibitory intracortical interactions. Other studies, however, have shown that the thalamus might actively contribute to the generation of the slow oscillation (Hughes et al., 2002; Crunelli and Hughes, 2010; David et al., 2013). These results argue for significant role of the thalamus in patterning the slow oscillation during deep sleep (Crunelli and Hughes, 2010).

The sleep slow oscillation groups other faster brain rhythms (Steriade et al., 1993a; Steriade, 2006), including fast oscillations in the $\beta$ and $\gamma$ frequency ranges (Steriade et al., 1996a; Steriade et al., 1996b; Dickson et al., 2003). Similar to the cortical slow oscillation, gamma oscillations can also be generated in isolated cortical structures in a condition of increased cortical excitability (Whittington et al., 1995; Draguhn et al., 1998). 


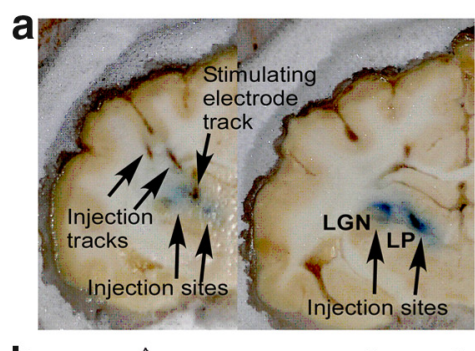

b 1 wath

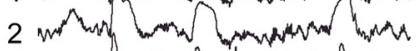
3 Nand mon 4 Aran

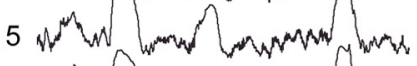
6 Wh

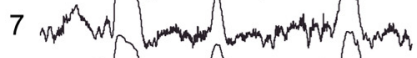
$8 w w^{4}$

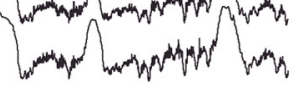

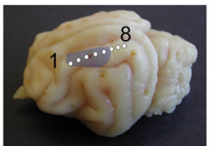

Control riping

$1 \mathrm{~h}$

$33 \mathrm{~h}$
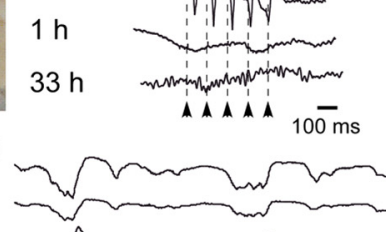

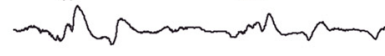

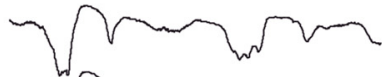

$\sqrt[n]{\text { man }} \sqrt{ }$

(n)

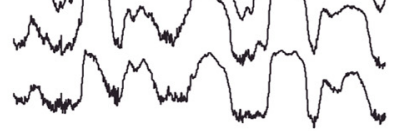

$2 \mathrm{~s}$ d 2

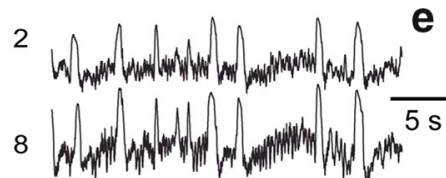

(1)

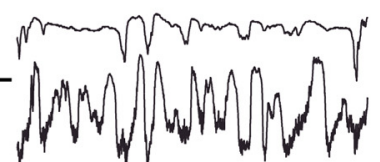
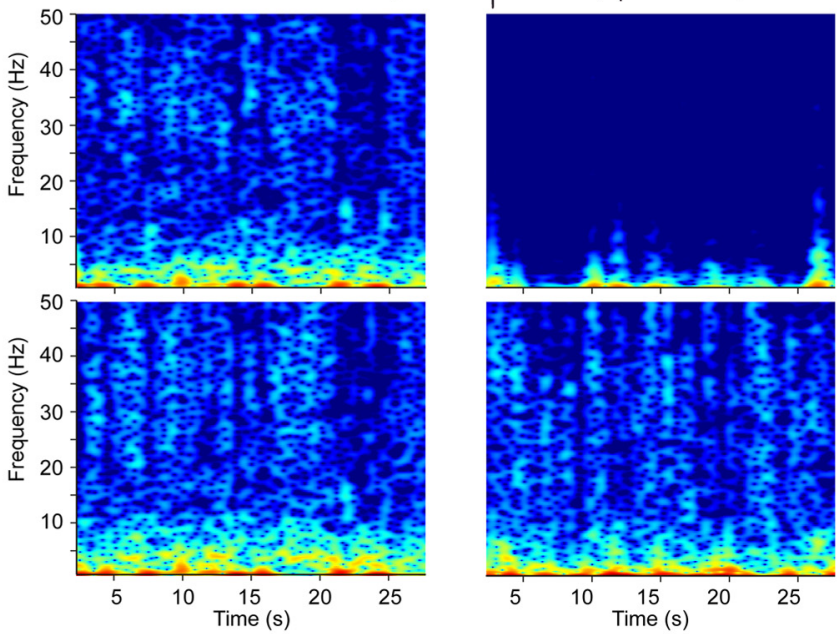

$10^{\star} \log 10(\mu \mathrm{V} 2 / \mathrm{Hz})$

Figure 1. Effects of partial thalamic inactivation on cortical slow oscillation. $\boldsymbol{a}$, Left, Location of QX-314 injection sites (violet area) and stimulating electrode in LP nucleus. Top right, Location of cortical recording electrodes $1-8$. Bottom right, Cortical response to LP stimulation in control and its abolition 1 and $33 \mathrm{~h}$ after inactivation. Multisite LFP recordings before (b) and $1 \mathrm{~h}$ after (c) LP inactivation. $\boldsymbol{d}, \boldsymbol{e}$, Wavelet transform of the LFP signal from electrodes 2 and $8 \mathrm{~d}$ before $(\boldsymbol{d})$ and after $(\boldsymbol{e})$ LP inactivation.

a

Control 1h after LP inactivaton
$30 \mathrm{~h}$ after inactivation

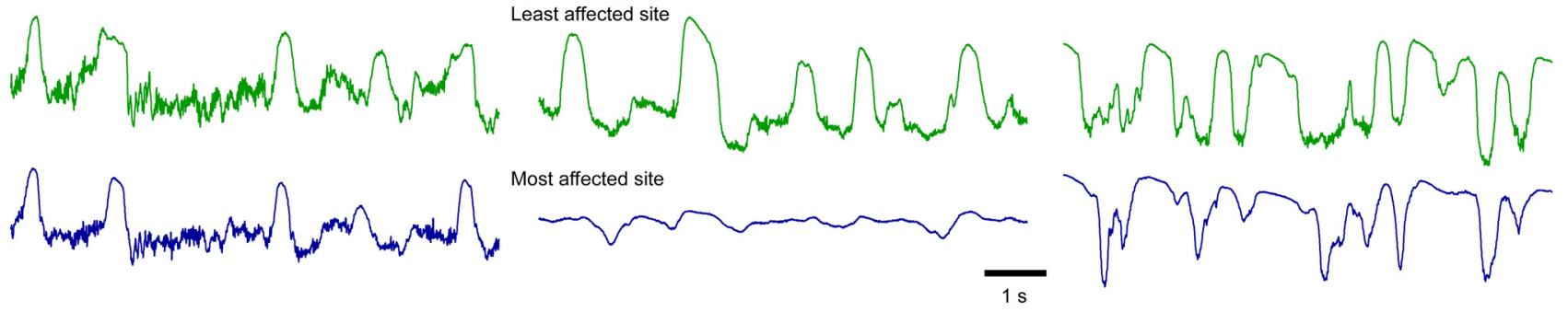

b

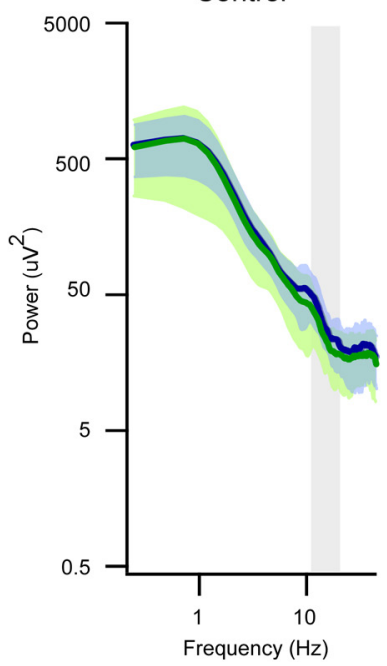

$1-2 \mathrm{~h}$

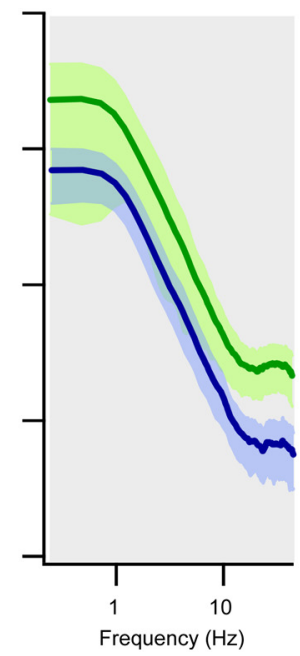

$7-8 h$

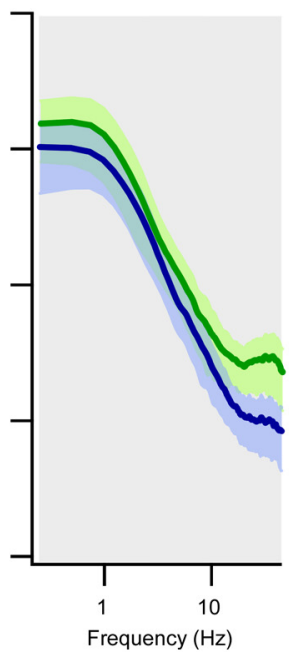

$12-13 h$

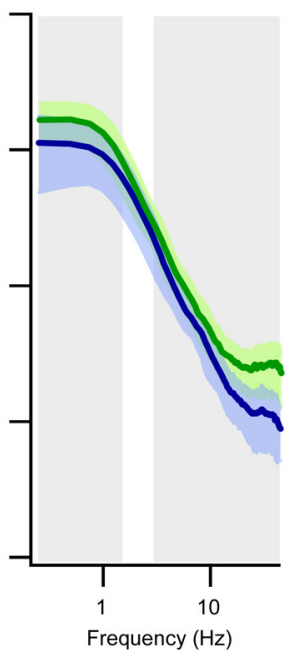

$>30 \mathrm{~h}$

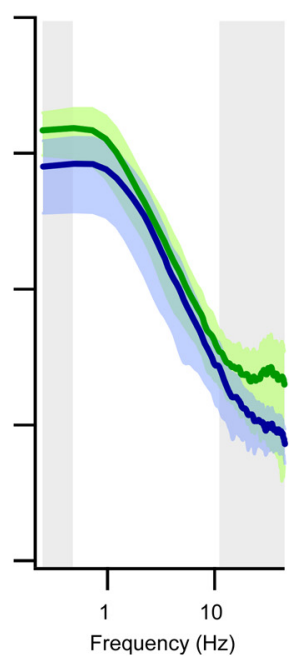

Figure 2. LFP power distribution in intact cortical regions versus cortical regions affected by thalamic inactivation. $\boldsymbol{a}$, Examples of LFP recordings from suprasylvian gyrus of cats from intact (green) and affected (blue) regions. $\boldsymbol{b}$, Power spectra distribution of LFP activities recorded in intact (green) and affected (blue) regions for frequencies $0.25-45 \mathrm{~Hz}$. Bin is $0.25 \mathrm{~Hz}$. Light green and blue indicate SD. Gray underlines significantly different bins (Mann-Whitney test, $p=0.05$ ). 
Table 1. Detailed geometry of thalamocortical network

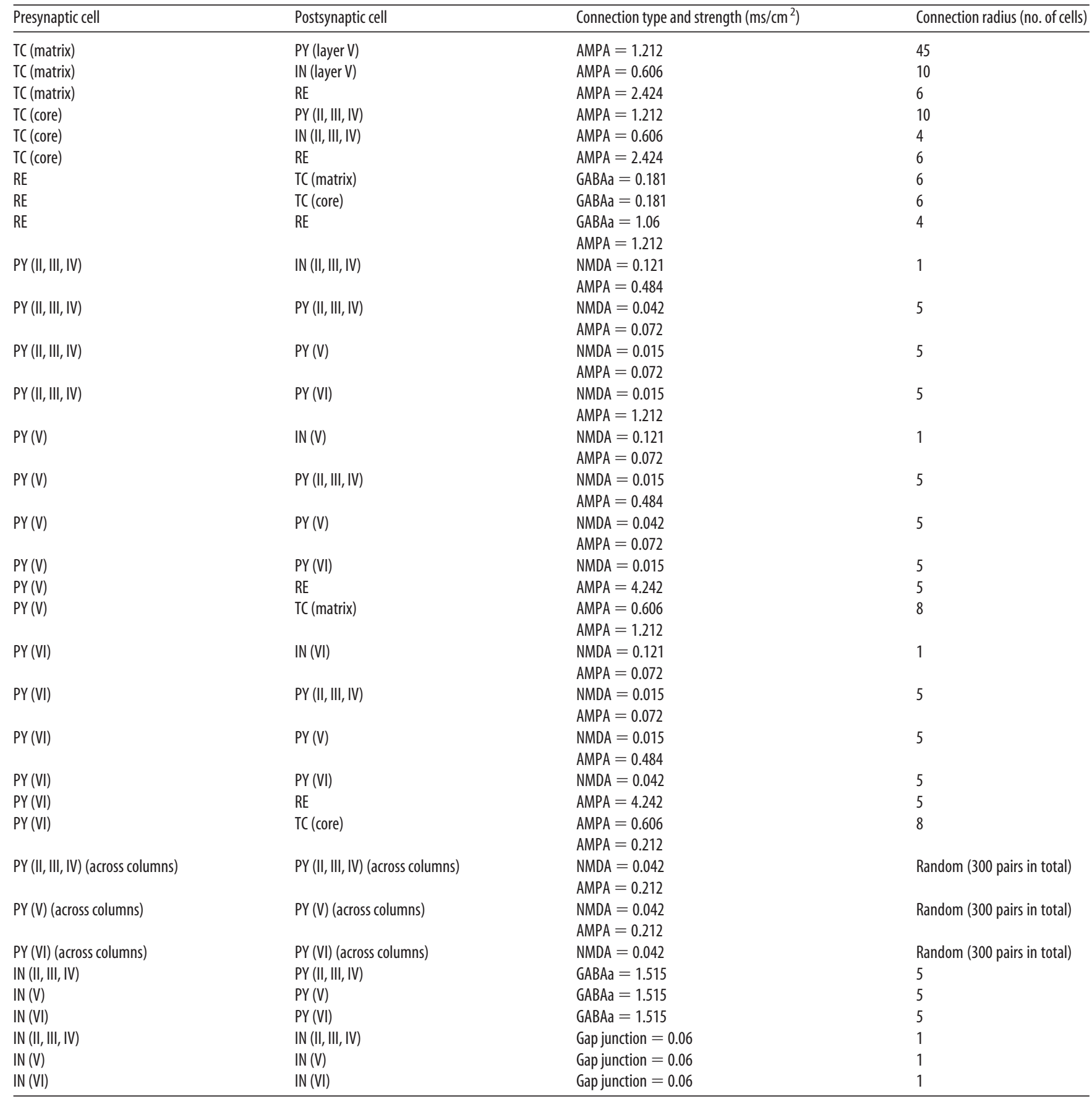

In this study, we demonstrate that thalamocortical inputs critically contribute to maintaining both the slow and fast $(\beta-\gamma)$ oscillations in the intact thalamocortical system. Full or partial cortical deafferentation that removes thalamocortical inputs also disrupts the slow and fast rhythms in the neocortical network, although rare spontaneous active states persisted in the cortex. The slow but not the fast oscillation started to recover within hours after disruption of the thalamocortical connectivity. We found in vivo evidence of recovery of the slow oscillation after cortical deafferentation and our modeling data indicate that an increase in intracortical excitatory synaptic drive may be one of the mechanisms underlying this phenomenon.

\section{Materials and Methods}

Surgery

Experiments were performed on cats of either sex in accordance with the guidelines published in the National Institutes of Health's Guide for the Care and Use of Laboratory Animals (NIH publication no. 86-23, revised 1987) and were approved by the Committee for Animal Care of Université Laval.

Acute experiments were conducted on cats anesthetized by intramuscular injection of ketamine and xylazine ( 10 and $2 \mathrm{mg} / \mathrm{kg}$, respectively). All recordings were obtained in areas 5 and 7 of the suprasylvian gyrus. Animals were continuously supplied with lactated Ringer's solution at a rate of $10 \mathrm{ml} / \mathrm{kg}$ intravascularly. Ketamine was added to the lactated Ringer's solution to insure a supplementary dose of $20 \mu \mathrm{g} / \mathrm{kg} / \mathrm{min}$. The 


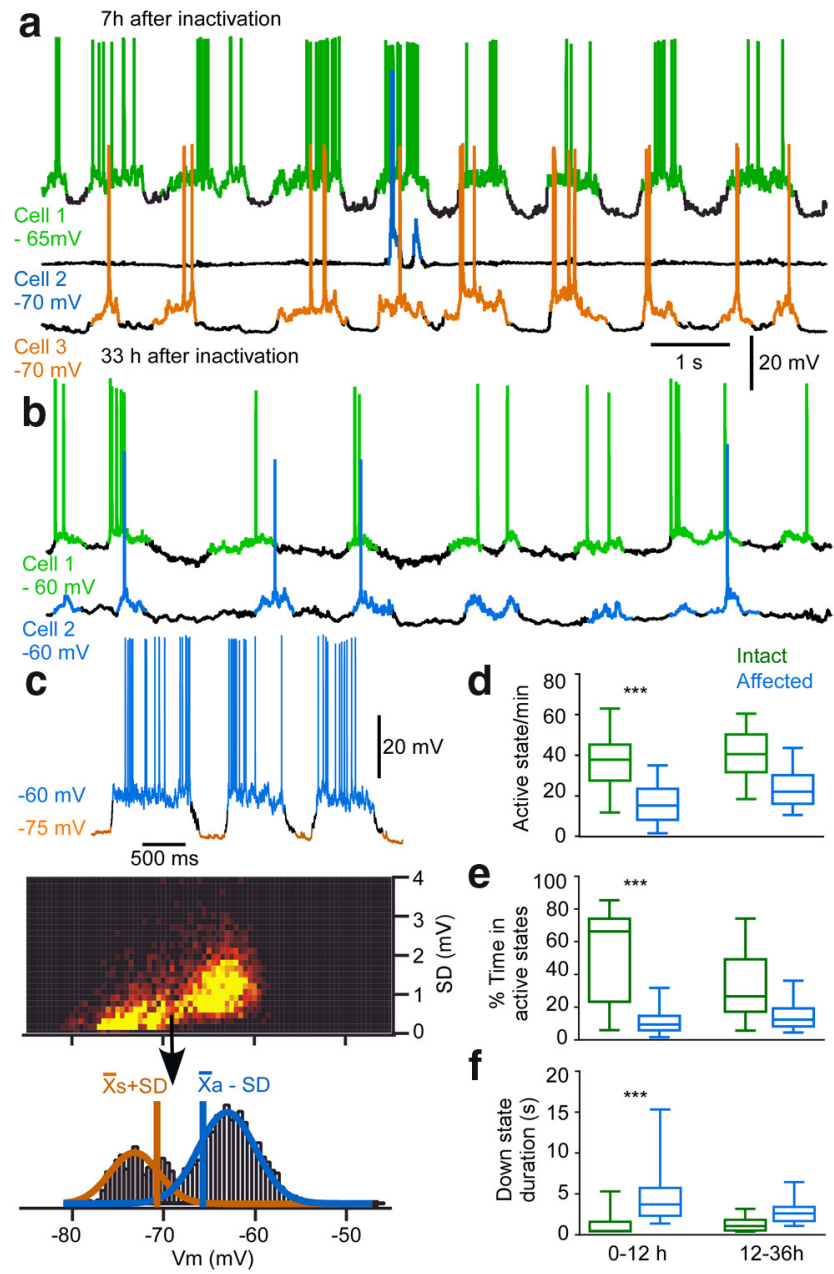

Figure 3. Intracellular activity in intact and partially deafferented cortical areas after inactivation of thalamic LP nucleus. $\boldsymbol{a}$, Triple intracellular recordings from affected (blue) and unaffected regions (anterior $=$ green, posterior $=$ orange) $7 \mathrm{~h}$ after LP inactivation. $\boldsymbol{b}$, Dual intracellular recording from unaffected (green) and recovering regions (blue) $33 \mathrm{~h}$ after inactivation. $c$, Detection method for active and silent states in intracellular recordings. $V_{\mathrm{m}}$ and $S D$ is computed in for each $25 \mathrm{~ms}$ window from intracellular recordings (top traces) and presented as a color-coded frequency matrix. Active and silent states clusters are split according to an initial threshold (arrow) visually selected. Frequency histograms of these new $V_{m}$ distributions are fitted with Gaussian curves. Silent state threshold (orange) is defined as the mean of its distribution (Xs) plus SD and active state threshold (blue) as the mean of its distribution $\left(X_{a}\right)$ minus SD. $\boldsymbol{d}-\boldsymbol{f}$, Boxplots of active states occurrence $(\boldsymbol{d})$, percentage of time in active state $(\boldsymbol{e})$, and silent state duration $(\boldsymbol{f})$ of neurons from intact and affected ( $0-12$ vs $12-36 \mathrm{~h}$ ) regions. Statistical significance was tested with ANOVA post hoc Dunn multiple-comparisons test: ${ }^{* *} p<$ 0.001 .

EEG was monitored throughout experiments, which lasted $8-36 \mathrm{~h}$, and additional doses of ketamine-xylazine were administered intravenously when the EEG tended slightly toward activated pattern. Lidocaine $(0.5 \%)$ was injected in all incision points. Animals were paralyzed with gallaminetriethiodide $2 \%$ and maintained under artificial ventilation. The ventilation rate and oxygenation were adjusted to keep an end-tidal $\mathrm{CO}_{2}$ at $3-3.5 \%$. Body temperature was maintained between 36.5 and $38^{\circ} \mathrm{C}$ throughout the experiment. The heart rate was continuously monitored ( $90-110$ beats $/ \mathrm{min})$. The stability of intracellular recording was obtained by draining the cisterna magna, bilateral pneumothorax, and hip suspension and filling the hole made in the skull with agar $4 \%$ in saline $0.9 \%$.

For experiments consisting in inactivating the thalamus ( $n=10$ cats), a stimulating electrode was stereotaxically inserted in the lateral posterior (LP) thalamic nucleus at the following coordinates: F 8, L 4.5, H 4.5 (Reinoso-Suarez, 1961). Cortical response to 5 current pulses $(10 \mathrm{~Hz}, 1.5$ $\mathrm{mA}, 0.2 \mathrm{~ms}$ ) delivered to the LP nucleus was assessed before the inacti- vation of LP nucleus (Fig. 1a). LP was inactivated by injection of $2 \mu \mathrm{l}$ of $20 \%$ lidocaine $N$-ethyl bromide (QX-314; Sigma) at 5 different coordinates: F7, L3, H3; F7, L3.75, H4.3; F7, L6, H4; F9, L6, H5; and F9, L6.75, H6.3. Coomassie blue (0.5\%) was added to the QX-314 solution to confirm the sites of injection histologically (Fig. 1a). Inactivation of LP was confirmed by the absence of cortical response to LP stimulation (Fig. 1a). The preparation of neocortical slabs $(\sim 6 \times 10 \mathrm{~mm})$ was described in detail previously (Timofeev et al., 2000). Slabs were isolated in acute cats $(n=7)$ and in chronically implanted cats $(n=2)$. The chronic surgery was described previously (Steriade et al., 2001; Timofeev et al., 2001).

At the end of the experiment, animals were transcardiacally perfused with saline $0.9 \%$, followed by paraformaldehyde $4 \%$ /glutaraldehyde $0.05 \%$ and then by sucrose $10 \%$ in PB $0.1 \mathrm{M}$. Brains were removed and kept in PB $0.1 \mathrm{M}$ sucrose $30 \%$ until they sank and were subsequently cryosectioned $(80 \mu \mathrm{m})$.

\section{Electrophysiology}

To record multisite field potential, an array of 8 low-impedance coaxial electrodes (Rhodes Medical Instruments), each spaced by $1.5 \mathrm{~mm}$, was inserted in the medial portion of the suprasylvian gyrus (band-pass filter: $0.1 \mathrm{~Hz}-10 \mathrm{kHz}$ ). A high-impedance amplifier (low-pass filter at $10 \mathrm{kHz}$ ) with an active bridge circuitry was used to record and inject current in cells. Single, dual, and triple intracellular recordings were obtained with sharp glass micropipettes filled with $2 \mathrm{M}$ potassium acetate (DC resistance of 30-75 M $\Omega$ ). Signals were recorded with a 16-channel data acquisition system (Vision; Nicolet) at a sampling rate of $20 \mathrm{kHz}$.

\section{Data analysis}

Analyses were performed offline on a personal computer using IgorPro (WaveMetrics) and MATLAB (MathWorks) software. Statistical analyses were performed in Prism 6 software (GraphPad). Depending on the normality of data and the equality of variances, we used either parametric (Student's $t$ test, ANOVA with Tukey's multiple-comparisons test) or nonparametric (Mann-Whitney test, Kruskall-Wallis test with post hoc Dunn's multiple correction) tests.

Wavelet transforms were computed for epochs of $15 \mathrm{~s}$ for frequency range of $0.1-70 \mathrm{~Hz}$ with the open source MATLAB toolbox EEGlab (Schwartz Center for Computational Neuroscience, University of California-San Diego). Fast Fourier transform was calculated for local field potential (LFP) recordings from the most and the least affected cortical sites.

Formal thresholds to determine the exact timing of onset of intracellular active and silent states were set as follows: the average and the SD of membrane potentials $\left(V_{\mathrm{m}}\right)$ were sampled in $25 \mathrm{~ms}$ time windows for epochs of at least $20 \mathrm{~s}$. Values were plotted in a frequency matrix (see Fig. $3 c$ ) and displayed two distributions corresponding to active and silent states. An initial threshold between these two distributions was chosen by visual inspection to split values in two new hyperpolarized and depolarized distributions. Average and SD were computed for these distributions. The active state onset occurred when $V_{\mathrm{m}}$ crossed the average value of the depolarized distribution minus its SD and stayed above this threshold for at least $50 \mathrm{~ms}$. Transition to the silent state began when $V_{\mathrm{m}}$ went below the average value of the hyperpolarized distribution plus its SD and stayed below this threshold for at least $50 \mathrm{~ms}$. The number of active states per minute, the percentage of time spent in active states, and the mean duration of silent states were averaged for each cell. To characterize the intensity of postsynaptic activity before and after the onset of active states, we measured the SD of the membrane potential in bins of $200 \mathrm{~ms}$ and averaged it over several cycles.

\section{Computational models}

Intrinsic currents: thalamus. Conductance-based models of thalamocortical (TC) and thalamic reticular (RE) neurons include one compartment described by the equation:

$$
C_{\mathrm{m}}(d V / d t)=-g_{\text {leak }}\left(V-E_{\text {leak }}\right)-I^{\text {int }}-I^{\text {syn }}
$$

where the membrane capacitance $\left(C_{\mathrm{m}}\right)=1 \mu \mathrm{F} / \mathrm{cm}^{2}$, nonspecific (mixed $\left.\mathrm{Na}^{+}, \mathrm{K}^{+}, \mathrm{Cl}^{-}\right)$leakage conductance $\left(g_{\text {leak }}\right)=0.01 \mathrm{mS} / \mathrm{cm}^{2}$ for TC cells and $0.05 \mathrm{mS} / \mathrm{cm}^{2}$ for RE cells, and the reversal potential $\left(E_{\text {leak }}\right)=-70$ 

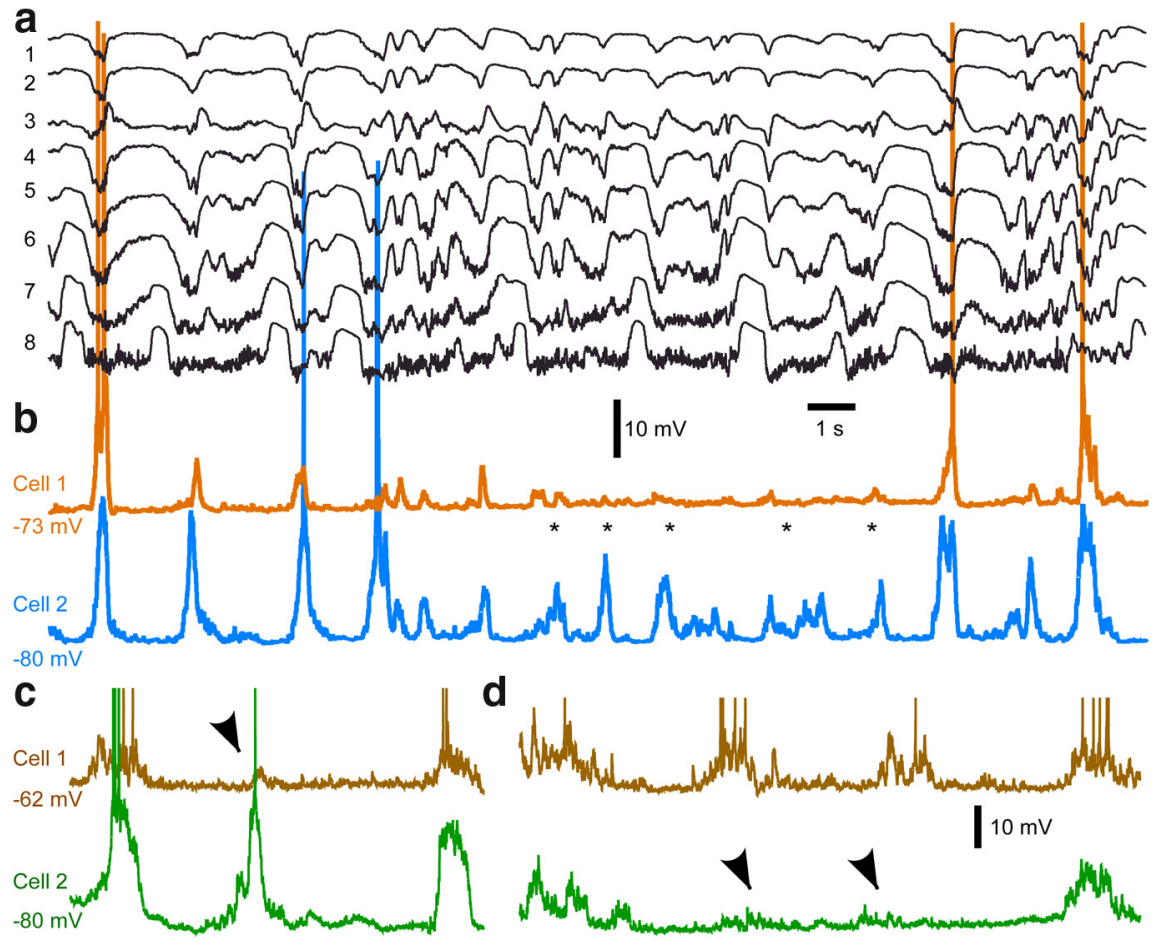

$-80 \mathrm{~m}$

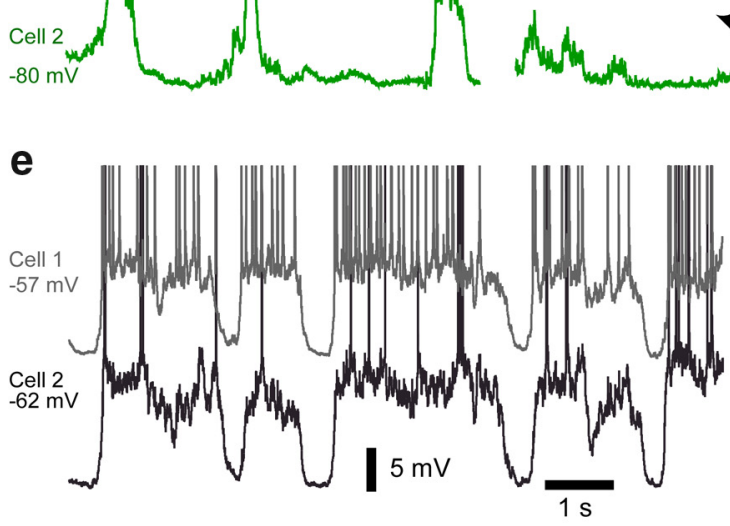

\section{f}

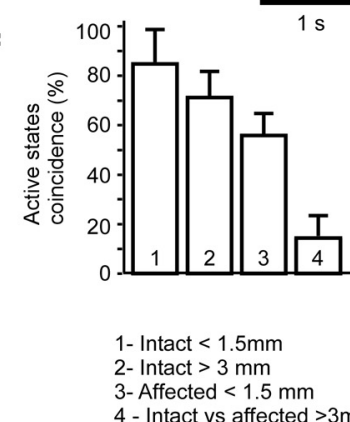

Figure 4. Alternating involvement in active states of closely located cortical neurons in the cortical area affected by thalamic inactivation. $\boldsymbol{a}, \boldsymbol{b}$, Multisite LFP $(\boldsymbol{a})$ and dual $(\boldsymbol{b})$ intracellular recordings of closely located neurons in affected regions (between sites 1 and 2). Multiple active states $\left(^{*}\right)$ occurred in Cell 2 but not in Cell 1. c, d, Dual intracellular recordings from another pair of closely located neurons from affected area. Active states occurred either simultaneously or in alternation (arrows). $\boldsymbol{e}$, Dual intracellular recording of closely located neurons in the intact brain. $f$, Mean coincidence of active states occurrence for cortical neurons in four conditions.

$\mathrm{mV}$ for TC cells and $-77 \mathrm{mV}$ for RE cells. $I^{\text {int }}$ is the sum of active intrinsic currents, and $I^{\text {syn }}$ is the sum of synaptic currents. The area of a RE cell and a TC cell was $1.43 \times 10^{-4}$ and $2.9 \times 10^{-4} \mathrm{~cm}^{2}$, respectively (Bazhenov et al., 2002).

Both RE and TC cells include fast sodium current $\left(I_{\mathrm{Na}}\right)$, a fast potassium current $\left(I_{\mathrm{K}}\right)$, a low-threshold $\mathrm{Ca}^{2+}$ current $\left(I_{\mathrm{T}}\right)$, and a potassium leak current $\left(I_{\mathrm{KL}}\right)=g_{\mathrm{KL}}\left(V-E_{\mathrm{KL}}\right)$, where $E_{\mathrm{KL}}=-95 \mathrm{mV}$. In addition, a hyperpolarization-activated cation current $\left(I_{\mathrm{h}}\right)$ was also included in TC cells. For TC cells, the maximal conductances were as follows: $g_{\mathrm{K}}=10$ $\mathrm{mS} / \mathrm{cm}^{2}, g_{\mathrm{Na}}=90 \mathrm{mS} / \mathrm{cm}^{2}, g_{\mathrm{T}}=2.2 \mathrm{mS} / \mathrm{cm}^{2}, g_{\mathrm{h}}=0.017 \mathrm{mS} / \mathrm{cm}^{2}$, and $g_{\mathrm{KL}}=-0.03 \mathrm{mS} / \mathrm{cm}^{2}$. For RE cells, the maximal conductances were as follows: $g_{\mathrm{K}}=10 \mathrm{mS} / \mathrm{cm}^{2}, g_{\mathrm{Na}}=100 \mathrm{mS} / \mathrm{cm}^{2}, g_{\mathrm{T}}=2.3 \mathrm{mS} / \mathrm{cm}^{2}$, and $g_{\text {leak }}=$ $0.005 \mathrm{mS} / \mathrm{cm}^{2}$. The expressions of voltage- and $\mathrm{Ca}^{2+}$-dependent transition rates for all currents have been described previously (Bazhenov et al., 2002).

Intrinsic currents: cortex. The cortical pyramidal cells (PYs) and interneurons (INs) were represented by two-compartment models with channels simulated by Hodgkin-Huxley kinetics. Each compartment was described by Equation 1 with the addition of the current from adjacent compartment, $I^{d, s}=g_{c}\left(V_{\mathrm{d}, \mathrm{s}}-V_{\mathrm{s}, \mathrm{d}}\right)$, where $V_{\mathrm{d}}\left(\right.$ resp. $\left.V_{\mathrm{s}}\right)$ is the voltage of the dendritic (resp. axosomatic) compartment. Based on our previous studies (Bazhenov et al., 2002; Chen et al., 2012), we assumed that the current dynamics in axosomatic compartment are fast enough to ensure that $V_{\mathrm{S}}$ is always at equilibrium state and can be defined by the equation $g\left(V_{\mathrm{S}}-V_{\mathrm{D}}\right)=-I_{\mathrm{S}}{ }^{\text {int }}$. The axosomatic and dendritic compartments were coupled by an axial current with conductance $g_{c}$.

The PY neurons and INs contained the fast $\mathrm{Na}^{+}$channels, $I_{\mathrm{Na}}$, with a higher density in the axosomatic compartment than in dendritic compartment. In addition, a fast delayed rectifier potassium $\mathrm{K}^{+}$current $\left(I_{\mathrm{K}}\right)$ was present in the axosomatic compartment. A persistent sodium current $\left(I_{\mathrm{Na}(\mathrm{p})}\right)$ was included in both axosomatic and dendritic compartments. A slow-voltage-dependent noninactivating $\mathrm{K}^{+}$ current $\left(I_{\mathrm{Km}}\right)$, a slow $\mathrm{Ca}^{2+}$-dependent $\mathrm{K}^{+}$ current $\left(I_{\mathrm{Kca}}\right)$, a high-threshold $\mathrm{Ca}^{2+}$ current $\left(I_{\mathrm{HVA}}\right)$, and a potassium leak current $\left(I_{\mathrm{KL}}=\right.$ $\left.g_{\mathrm{KL}}\left(V-E_{\mathrm{KL}}\right)\right)$ were included in the dendritic compartment only. The expressions of the voltage- and $\mathrm{Ca}^{2+}$-dependent transition rates for all currents are given in Timofeev et al. (2000). For the axosomatic compartment, the maximal conductances and passive properties were $S_{\text {soma }}=1.0 \times 10^{-6} \mathrm{~cm}^{2}, g_{\mathrm{Na}}=3000$ $\mathrm{mS} / \mathrm{cm}^{2}, g_{\mathrm{K}}=200 \mathrm{mS} / \mathrm{cm}^{2}$, and $g_{\mathrm{Na}(\mathrm{p})}=0.07$ $\mathrm{mS} / \mathrm{cm}^{2}$. For the dendritic compartment: $C_{\mathrm{m}}$ $=0.75 \mu \mathrm{F} / \mathrm{cm}^{2}, g_{\mathrm{L}}=0.033 \mathrm{mS} / \mathrm{cm}^{2}, g_{\mathrm{KL}}=$ $0.0025 \mathrm{mS} / \mathrm{cm}^{2}, S_{\text {dend }}=S_{\text {soma }} r, g_{\mathrm{HVA}}=0.01$ $\mathrm{mS} / \mathrm{cm}^{2}, g_{\mathrm{Na}}=1.5 \mathrm{mS} / \mathrm{cm}^{2}, g_{\mathrm{Kca}}=0.3 \mathrm{mS} /$ $\mathrm{cm}^{2}, g_{\mathrm{Km}}=0.01 \mathrm{mS} / \mathrm{cm}^{2}, g_{\mathrm{Na}(\mathrm{p})}=0.07 \mathrm{mS} /$ $\mathrm{cm}^{2}$, and $E_{\mathrm{KL}}=-95 \mathrm{mV}$. $E_{\text {leak }}$ was $-68 \mathrm{mV}$ for PYs and $-75 \mathrm{mV}$ for INs (Bazhenov et al., 2002). For INs, no $I_{\mathrm{Na}(\mathrm{p})}$ was included. The resistance $(r)$ between compartments was set to $10 \mathrm{M} \Omega$.

The firing properties of this model depended on the coupling conductance between compartments $\left(g_{c}=1 / r\right)$ and the ratio of the dendritic area to the axosomatic area $R$ (Mainen and Sejnowski, 1996). We used a model of a regular-spiking neuron for PY cells $(R=165)$ and a model of a fast-spiking neuron for IN cells $(R=50)$.

Synaptic currents. All synaptic currents were calculated according to the following equation:

$$
I_{\text {syn }}=g_{\text {syn }}[O]\left(V-E^{\text {syn }}\right)
$$

where $g_{\text {syn }}$ is the maximal conductance, $[O]$ is the fraction of open channels, and $E^{\text {syn }}$ is the reversal potential. In RE and PY cells, the reversal potential was $0 \mathrm{mV}$ for AMPA and NMDA receptors and $-70 \mathrm{mV}$ for $\mathrm{GABA}_{\mathrm{A}}$ receptors. For TC cells, the reversal potential was $-80 \mathrm{mV}$ for $\mathrm{GABA}_{\mathrm{A}}$ receptors and $-95 \mathrm{mV}$ for $\mathrm{GABA}_{\mathrm{B}}$ receptors. A simple phenomenological model characterizing short-term depression of intracortical excitatory connections was also included in the model. According to this, a maximal synaptic conductance was multiplied to a depression variable $(D)$, which represents the amount of available synaptic resources. Here, $D=1-\left(1-D_{\mathrm{i}}(1-U)\right) \exp \left(-\left(t-t_{\mathrm{i}}\right) / \tau\right)$, where $U=0.2$ is the fraction of resources used per action potential, $\tau=500 \mathrm{~ms}$ is the time constant of recovery of the synaptic resources, $D_{\mathrm{i}}$ is the value of $D$ immediately before the $i_{\text {th }}$ event, and $\left(t-t_{\mathrm{i}}\right)$ is the time after $i_{\text {th }}$ event.

$\mathrm{GABA}_{\mathrm{A}}, \mathrm{NMDA}$, and AMPA synaptic currents were modeled by the first-order activation schemes. Dependence of postsynaptic voltage for NMDA receptors was $\left.1 /\left(1+\exp \left(V_{\text {post }}-V_{\text {th }}\right) / \sigma\right)\right)$, where $V_{\text {th }}=$ $-25 \mathrm{mV}$ and $\sigma=12.5 \mathrm{mV}$. $\mathrm{GABA}_{\mathrm{B}}$ receptors were modeled by a higher-order reaction scheme that considers the activation of $\mathrm{K}^{+}$ channels by G-proteins. The equations for all synaptic currents have been described previously (Bazhenov et al., 1998; Timofeev et al., 
2000). The values of maximal conductance for each synapse are listed in Table 1.

Spontaneous miniature EPSPs and IPSPs were also set in the present model. The arrival times of miniature EPSPs and IPSPs followed the Poisson process (Stevens, 1993), with time-dependent mean rate $\mu=(2 /(1+$ $\left.\left.\exp \left(-\left(t-t_{0}\right) / 400\right)\right)-1\right) / 250$, where $t$ is real time and $t_{0}$ is the timing of the last presynaptic spike.

Network geometry. The thalamocortical network model was constructed using several populations of neurons, including cortical pyramidal cells (layers II-IV, layer V, and layer VI), cortical interneurons (layer II-IV, layer V, and layer VI), thalamocortical neurons (with matrix and core subsystems), and thalamic reticular neurons. A general connecting scheme among different populations of neurons is introduced in Figure 7. In total, there were 1500 pyramidal neurons (500 in each population), 360 interneurons ( 120 in each population), 250 thalamic reticular neurons, and 500 thalamocortical neurons (250 in each structure).

In addition, in this model, cortical layers were evenly split into 10 cortical columns, with a high density of short-range (within a predetermined footprint; Table 1) connections within each column and low-density, lowstrength random connections between columns. Details of the network architecture (including the probability of connections and synaptic weights) are provided in Table 1.

In computational models, the LFP of an individual column was estimated by averaging membrane voltages of all neurons within this column.

Upregulation of synaptic efficacy and intrinsic conductances. The increase in the $\mathrm{SD}$ of $V_{\mathrm{m}}$ was implemented by adjusting the strength of PY-PY connection, the strength of IN-PY connection, and the amplitude and frequency of the spontaneous miniature EPSPs (Fröhlich et al., 2008; Volman et al., 2011a; Volman et al., 2011b). Excitatory factors were increased (decreased) and inhibitory factors were decreased (increased) if the average PY firing rate was below (above) the target rate that was estimated by averaging the firing rate in the intact network. The adjusting parameters were $\pm 0.5 \%$ for the strength of PY-PY connections and $\pm 0.3 \%$ for the amplitude of miniature EPSP. The updating cycle was $2 \mathrm{~s}$.

In addition, we also tested the following five different scaling models by manipulating different biophysical variables in the model: (1) conductance of leaking potassium current $\left(g_{\mathrm{KL}}\right)$ at the dendritic compartment of pyramidal neurons (the adjusting scale was $\pm 0.5 \%$ ); (2) conductance of the fast sodium current $\left(g_{\mathrm{Na}}\right)$ and voltage-dependent potassium current $\left(g_{\mathrm{Km}}\right)$ simultaneously at dendritic compartment of pyramidal neuron (the adjusting scale was $\pm 0.25 \%$ for both of them); (3) conductance of persistent sodium current $\left(g_{\mathrm{Nap}}\right)$ and calcium-dependent potassium current $\left(g_{\mathrm{KCa}}\right)$ simultaneously at dendritic compartment of pyramidal neuron (the adjusting scale was $\pm 0.1 \%$ for both of them); (4) strength of IN-PY connection $\left(g_{\text {GABA-A }}\right)$ alone (the adjusting scale was $\left.\pm 2 \%\right)$; and (5) strength of PY-PY connection $\left(g_{\mathrm{AMPA}}\right)$ and minis amplitude (the adjusting scale was $\pm 0.5 \%$ for $g_{\text {AMPA }}$ and $\pm 0.3 \%$ for minis amplitude).

\section{Results}

Thalamic inactivation disrupts cortical slow and fast activities

We chose to study the contribution of thalamic and cortical circuits to the slow oscillatory activity by inactivating the LP tha- lamic nucleus with the use-dependent sodium channels blocker QX-314 and recording the resulting activity in the respective cortical area (suprasylvian gyrus) in cats. In an intact preparation, LFP recordings (array of 8 electrodes separated by $1.5 \mathrm{~mm}$; Fig. 1a) from the suprasylvian gyrus under ketamine-xylazine anesthesia demonstrated the presence of a robust and synchronized slow oscillation (Fig. 1b). Electrical pulse-trains applied through an electrode located within the (LP) nucleus of the thalamus at 10 $\mathrm{Hz}$ elicited a cortical augmenting response (Fig. $1 a$, inset, top trace). Wavelet transform analysis also pointed to the presence of a robust high-frequency component in the $\beta$-gamma frequency range during slow oscillation (Fig. $1 d$ ). In agreement with a previous study (Doi et al., 2007), when the LP thalamic nucleus was inactivated (Fig. 1a, left), the slow waves and fast rhythms in the targeted cortical regions were reduced dramatically (Figs. 1c,e, $4 a$ ). Electrical stimuli applied to the inactivated thalamic site (Fig. 1a) did not elicit any cortical response after QX-314 injection (Fig. $1 a$, inset, middle and bottom trace), indicating that these thalamic sites were functionally inactivated. In the affected cortical regions, both slow oscillation and $\beta$-gamma activity, which typically occurs during active cortical states, were virtually abolished (Fig. 1e, top) and were only slightly reduced in the periphery of the affected sites (Fig. 1e, bottom). This suggests that thalamic inputs are required for the generation and synchroniza- 

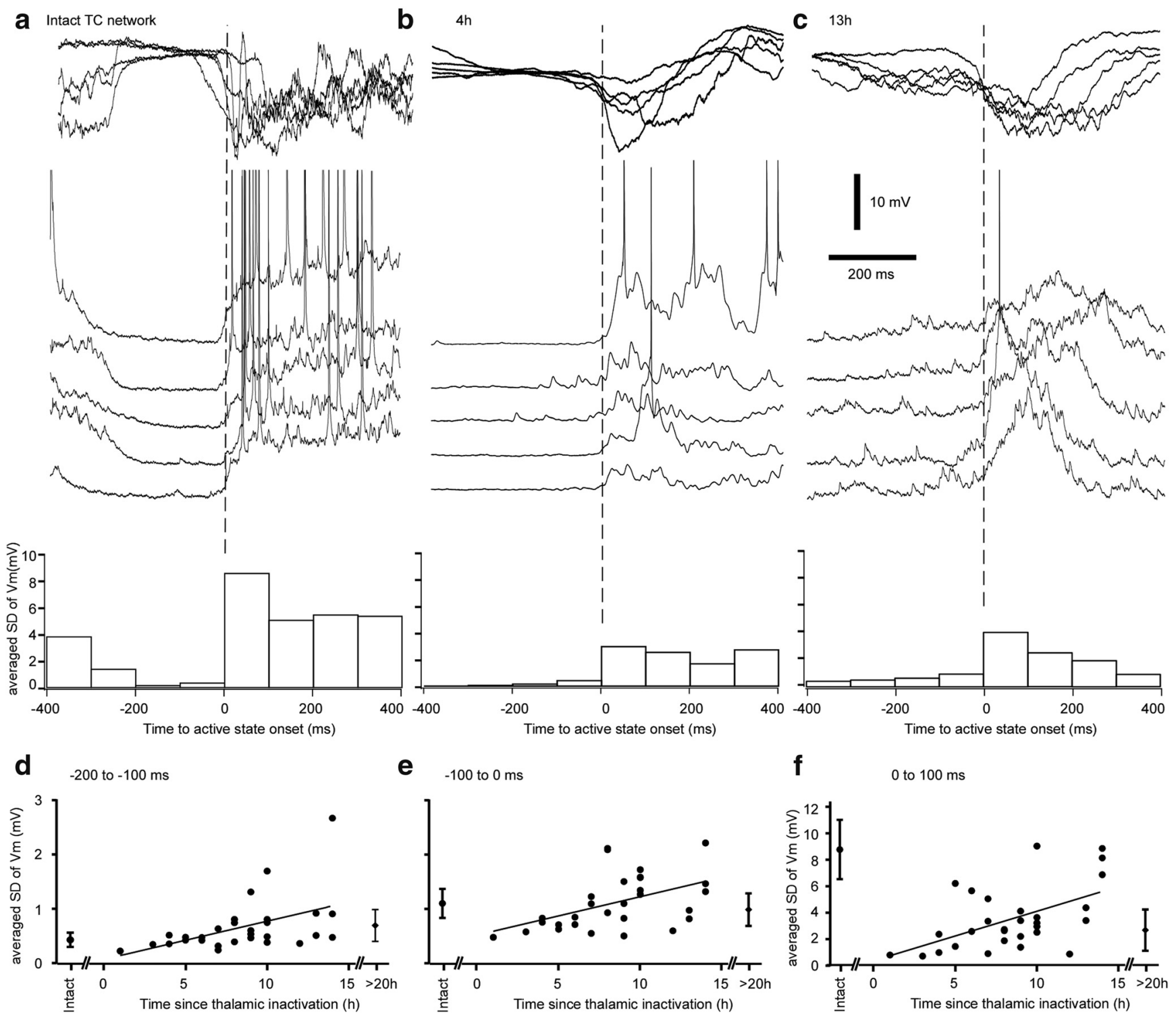

Figure 6. Upregulation of synaptic activites after thalamic inactivation. Examples of LFP and intracellular recordings at the transition to the active state before inactivation $(\boldsymbol{a}), 4 \mathrm{~h}(\boldsymbol{b})$, and $13 \mathrm{~h}$ (c) after thalamic inactivation. Below traces are the corresponding averaged SD of membrane potential in bins of $100 \mathrm{~ms}$. $\boldsymbol{d}$ - $\boldsymbol{f}$, Averaged SDs are plotted against the time since the thalamic inactivation for the period -200 to $-100 \mathrm{~ms}$ before active state onset $(\boldsymbol{d}),-100 \mathrm{~ms}$ to active state onset $(\boldsymbol{e})$, and the first $100 \mathrm{~ms}$ of the active states $(\boldsymbol{f})$.

tion of cortical active states during slow oscillation. To verify whether thalamic injection of QX-314 effects were not attributed to a leak of QX-314 to cortical locations, in control experiments, we injected intracortically $0.1 \mu \mathrm{l}$ of $20 \%$ QX-314. This induced local and complete cortical inactivation with a radius of $1.5 \mathrm{~mm}$ (data not shown).

To quantify changes in slow and fast rhythms induced by thalamic inactivation, we performed power spectral analysis from 10 animals (Fig. 2) in which we compared activities in the most versus the least affected electrodes over time. Before thalamic inactivation, the differences were restricted to frequencies $12-17 \mathrm{~Hz}$, which might be explained by a particular network organization of the two cortical sites. After thalamic inactivation, the power spectra of all investigated frequencies was reduced (Mann-Whitney, $p<0.05$; Fig. $2 b, 1-2$ and $7-8 \mathrm{~h}$ ).

We performed multisite intracellular recordings to investigate the source of the reduction of the LFP signal in the affected region (Figs. 3, 4). Of 86 neurons recorded in this study, 59 were located in the territory with disturbed slow oscillatory activity, as estimated from the LFP recording. In the example shown in Figure $3 a$, the intracellular pattern in the affected region (intra 2) showed only one active state during $10 \mathrm{~s}$ epoch of recording, whereas active states cooccurred every $1-2 \mathrm{~s}$ in unaffected regions (intra 1 [anterior suprasylvian gyrus] and intra 3 [posterior suprasylvian gyrus]) separated by a distance of $11 \mathrm{~mm}$.

To characterize the impact of thalamocortical inputs functional removal on the occurrence of active states and the percentage of time spent in this state, we detected active and silent states in each neuron according to formal thresholds (Fig. 3c, see Materials and Methods). In the affected region ( $0-12 \mathrm{~h}$ from time of inactivation), active states occurred with a mean frequency of $16.1 \pm 9.1$ per minute, lower than in intact regions $(37.1 \pm 12.1$, $p<0.0001$; Fig. $3 d$, Kruskal-Wallis post hoc Dunn's multiplecomparisons test). Overall, active states in regions with disrupted slow oscillation occupied $11.0 \pm 6.9 \%$ of the total time, whereas, 


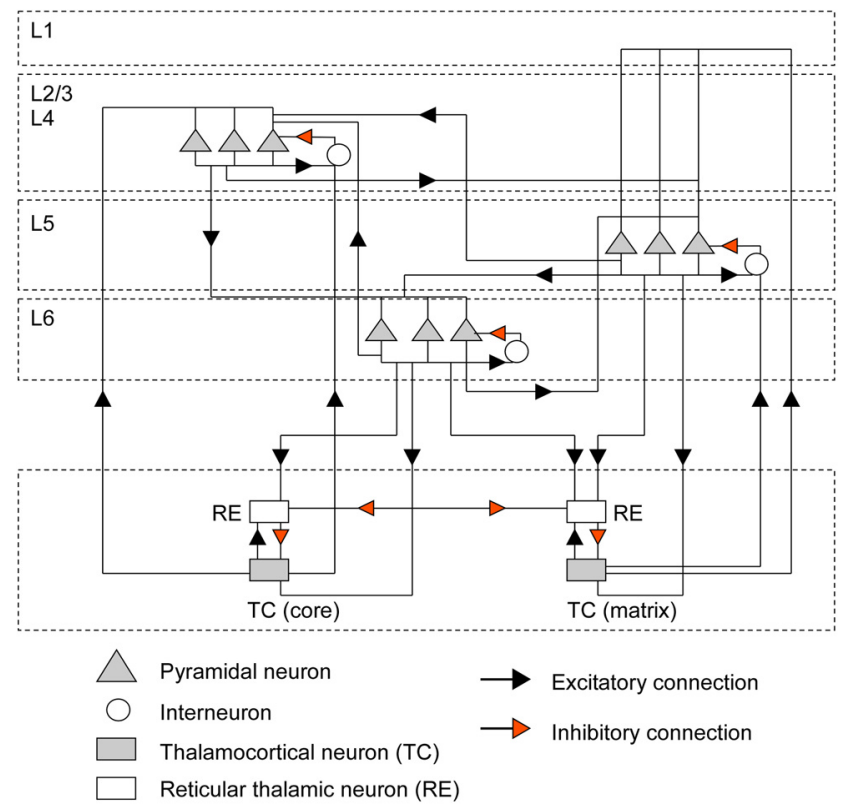

Figure 7. Geometry of the thalamocortical network model. The thalamortical network model includes a cortical layer II/III/IV, cortical layer V, cortical layer VI, RE, and TC neurons. In each cortical layer, there are 500 PYs and 120 INs. They are evenly divided into 10 cortical columns (50 PY and 12 IN in each column). The thalamic network includes layer of thalamic reticular neurons ( 250 neurons) and relay cells (500 neurons) divided into two nuclei: specific (core) and diffusive (matrix). The black arrowhead represents excitatory connections and the red arrowhead indicates inhibitory connections. The connectivity radius (fan-out) information is listed in Table 1.

in intact regions, they occupied $51.6 \pm 26.6 \%$ of the total time (Fig. 3e, $p<0.0001$, Kruskal-Wallis post hoc Dunn's multiplecomparisons test). The down-state duration was also longer in neurons located in the affected region (Fig. $3 f, p<0.0001$, Kruskal-Wallis post hoc Dunn's multiple-comparisons test). These results suggest that the thalamocortical neurons contribute significantly to the generation of the cortical active states of the slow oscillation.

Dual recordings from closely located neurons $(0.5-1.5 \mathrm{~mm})$ in affected areas demonstrate that active states can be generated in neighboring neurons either in alternation (Fig. $4 c, d$, arrowheads) or a large number of them can be recorded in one neuron but not in another one (Fig. $4 b$, asterisks). This contrasts to observations in intact cortical areas, in which alternating active and silent states occurred with a high degree of synchrony in neighboring neurons (Fig. 4e). Using coincidence analysis (Mukovski et al., 2007), we found that, in the intact suprasylvian gyrus, neurons within a distance of $<1.5 \mathrm{~mm}$ ( $n=10$ pairs $)$ spent coincidentally $84.4 \pm 13.1 \%$ of the time in active states. In contrast, neurons within a similar interneuronal distance in the affected area displayed a lower coincidence of active states $(n=15$ pairs, $p<0.001$, ANOVA post hoc Tukey's multiple-comparisons test; Fig. $4 f 3)$. This synchronicity was significantly lower even than for neurons recorded in intact areas separated by $>3 \mathrm{~mm}(n=10$ pairs, $p=0.005$, ANOVA post hoc Tukey's multiple-comparisons test; Fig. 4f2). The lowest synchronicity of active states was observed between neurons located in intact area and those in the affected area ( $n=11$ pairs, $p<0.0001$, ANOVA post hoc Tukey's multiple-comparisons test; Fig. $4 f 4$ ). The reduced amplitude of the slow waves in the affected region (Fig. 1) can be attributed to the lack of actives state synchronicity among neurons devoid of thalamocortical inputs. In addition to its role in generating active states, these results reveal that blocking the activity of a thalamic region dramatically reduced the synchronization of cortically generated active states.

\section{Time-dependent recovery of slow oscillation}

Twelve to 13 hours after thalamic inactivation, the field potential activities started to recover progressively. The absence of cortical response to thalamic stimuli (Fig. $1 a$, inset, bottom trace) indicated that the inactivation by QX314 was still effective. After $30 \mathrm{~h}$ ( $n=4$ cats), the activities in low-frequency range of $0.5-12.0 \mathrm{~Hz}$ were similar in intact and affected cortical regions (Fig. 2b). In contrast, the power for the faster activities $(>12.0 \mathrm{~Hz})$ were significantly depressed in the most affected by thalamic inactivation site. The remaining differences in the infraslow range $(<0.5 \mathrm{~Hz})$ are likely attributed to the metabolic alterations induced by prolonged anesthesia (Aladjalova, 1957).

We also recorded the intracellular activity of neurons in the affected region $12-36 \mathrm{~h}$ after inactivation of the thalamus. As shown in Figure $3 b, 33 \mathrm{~h}$ after thalamic inactivation, the simultaneously recorded intracellular activity of two cortical neurons from the intact and affected areas revealed a similar pattern of the slow oscillation. For the neurons recorded in the late period in the affected region (12-36 h), the difference in the number of active states, the time spent in active states, and the down state duration was not significant compared with the intact region (KruskalWallis post hoc Dunn's multiple-comparisons test; Fig. $3 d-f$ ). These results suggest that the slow oscillation gradually recovers in the absence of thalamocortical input and point to the presence of intracortical compensatory mechanisms.

We extended our investigation of the cortical recovery of the slow oscillation to fully isolated neocortical slabs (Timofeev et al., 2000; Fig. 5). In the first hour after isolation, we detected in the LFP recordings of slabs of anesthetized cats an average of $1.4 \pm$ 2.3 active states per minute (Fig. $5 a, e, f$ ), which was even lower than after thalamic inactivation. In total, we analyzed timedependent changes in the active state generation in seven acute and two chronic slabs. Within time window segments selected for analysis (Fig. 5f), there was a highly significant increase in the number of active states after $\sim 100 \mathrm{~h}$ after isolation (KruskalWallis test, $p<0.0001)$. Dunn's multiple-comparisons test shows that changes were found between all investigated groups except for two pairs of data indicated in Figure $5 f$. In chronic slabs, electrographic activities were not recorded during recovery from surgery. Recordings performed 100 or more hours from isolation revealed $35-45$ active states per minute (Fig. 5b-f), which is comparable to the slow oscillation in naturally sleeping cats with intact cortex (Steriade et al., 1993b). The slow oscillation in the slab did not depend on the state of vigilance; it was present during both slow-wave sleep (Fig. 5b,c) and brainactivated states (Fig. $5 b, d$ ). These results suggest that the normal slow oscillation in the intact brain arises through interactions between thalamic and cortical circuits and that it gradually recovers in the absence of any extracortical inputs.

Concurrent to the recovery of the slow oscillation in partially deafferented cortical regions, we observed an increase in both the frequency and amplitude of postsynaptic events occurring before the active states as a function of time from thalamic inactivation (Fig. $6 a-c)$. Because active states are associated with intense excitatory and inhibitory synaptic activities originating from a large number of interconnecting neurons, the extraction and quantification of individual events might give unreliable results with a bias toward larger amplitude events. Therefore, we analyzed segments of intracellular recordings that contained a silent state and 


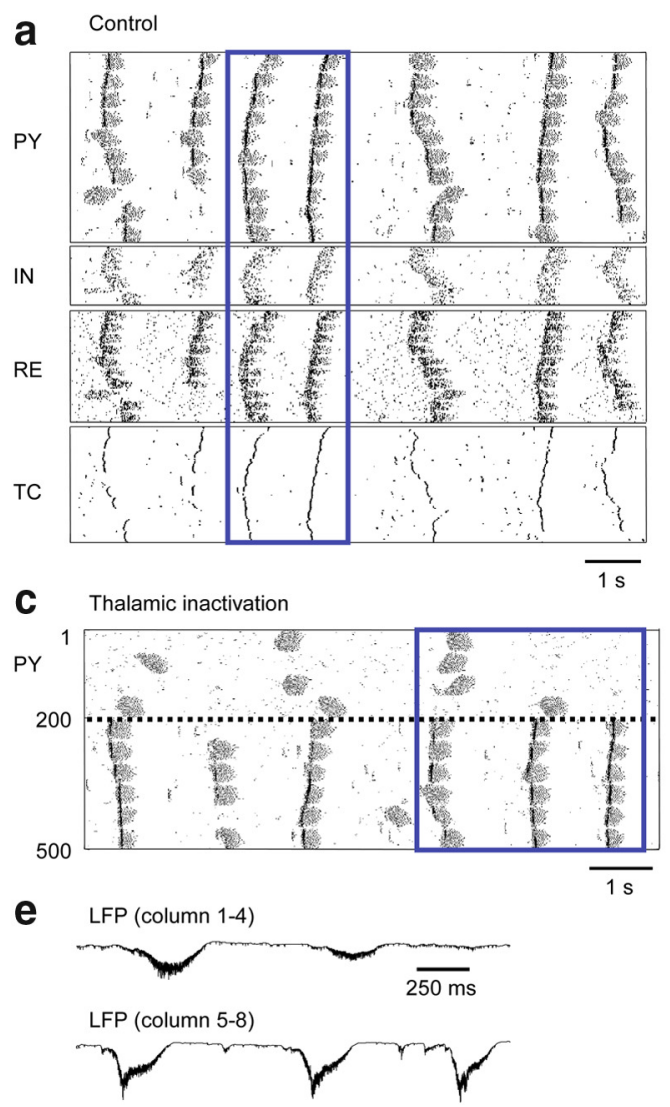

b

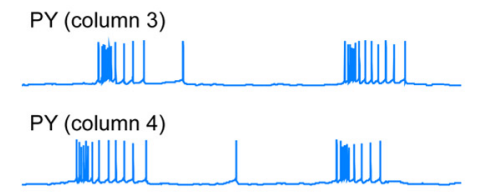

PY (column 7)

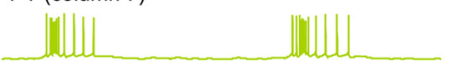

PY (column 8)

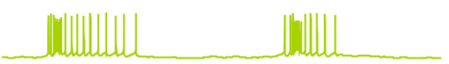

TC

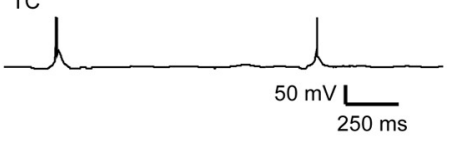

d
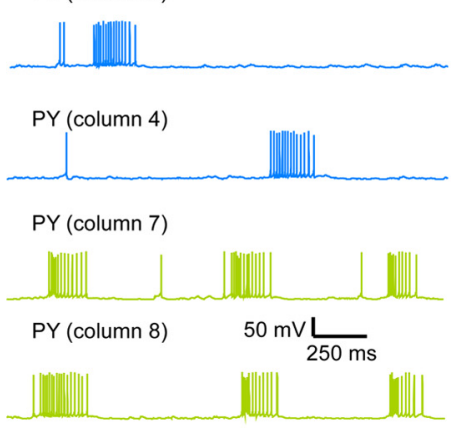

Figure 8. Modeling study of the effect of thalamic deafferentation on the neocortical slow oscillation. $\boldsymbol{a}$, Slow oscillation in large-scale thalamocortical model. Rastergrams of PYs, INs, REs, and TCs (top). $\boldsymbol{b}$, Examples of membrane voltage of PY neurons from selected columns and of a TC neuron in control condition. $c$, Removal of synaptic connectivity from TC neurons to the first four cortical columns (top) reduced active states occurrence. $\boldsymbol{d}$, Examples of membrane voltage of pyramidal neurons from selected columns after removal of thalamic inputs. , LFPs in deafferented columns $1-4$ were reduced in amplitude compared with intact columns 5-8.

its transition to an active state at different times from thalamic inactivation (Fig. 6) and measured the SD of the membrane potential fluctuations in bins of $100 \mathrm{~ms}$ near the onset of the active states (Fig. $6 a-c$, histograms). The analysis was performed on 10 neurons in control conditions (no inactivation), 29 cells in period $0-15 \mathrm{~h}$, and 13 cells $>20 \mathrm{~h}$ from thalamic inactivation (Fig. $6 d-f$ ). We found a progressive increase in the SD of membrane potential fluctuations over time in different segments preceding and immediately after the onset of an active state (Fig. $6 d-f$ ). The Kruskal-Wallis test further showed a highly significant increase in synaptic activities as a function of time from thalamic inactivation $(-200 \mathrm{~ms}$ to $-100 \mathrm{~ms}, p=0.0136 ;-100$ to $0 \mathrm{~ms}, p<$ 0.0001 ; and 0 to $100 \mathrm{~ms}, p<0,0001)$. Dunn's multiplecomparisons test revealed that the values returned to control levels after $10-14 \mathrm{~h}$ from thalamic inactivation, closely matching our findings with LFP recordings (Fig. 2). We attribute the lower values of synaptic noise after $20 \mathrm{~h}$ to the long-lasting effects of ketamine-xylazine anesthesia. Overall, these results show that the progressive recovery of the neocortical slow oscillation is accompanied by an increase in neocortical postsynaptic activity.

\section{Modeling experiments of the synchronization and scaling of cortical slow oscillation}

Previous models of the thalamocortical slow oscillation were based on uniform synaptic connectivity (Timofeev et al., 2000; Bazhenov et al., 2002; Compte et al., 2003). In light of our exper- imental findings, we implemented in a large-scale thalamocortical network model a more realistic columnar organization (Fig. 7, Table 1, see model description in Materials and Methods). Specifically, we implemented a highdensity local connectivity and sparse longrange connections as observed in vivo (Thomson and Bannister, 2003). The model displayed an alternation of active and silent states at a frequency of $0.62 \pm$ $0.08 \mathrm{~Hz}$. The active-state initiation was driven by spontaneous transmitter release at excitatory synapses, whereas termination was mediated by synaptic depression, activation of intrinsic hyperpolarizing conductances, and synaptic inhibition (Timofeev et al., 2000; Bazhenov et al., 2002; Chen et al., 2012). This produced rhythmic activity resembling sleep slow oscillation in vivo that was synchronized across the thalamocortical network (Fig. $8 a, b)$.

Upon complete thalamic deafferentation of the first four cortical columns, the regular slow oscillation pattern was disrupted in affected cortical areas (Fig. $8 c, d$ ). In the intact network, both cortico-thalamo-cortical projections and long-range intracortical connectivity contributed to the synchrony of slow oscillation. However, immediately after thalamic inactivation, the remaining intracortical connections were not sufficient to drive rhythmic activity in the deafferented areas. Therefore, in agreement with experimental data (Figs. $3 a, 4 b-d$ ), deafferented cortical neurons were mostly silent and only displayed occasional and irregular active states that were limited to specific columns and did not propagate to the rest of the network. The simulated LFP amplitude was reduced in deafferented areas (Fig. $8 e$ ), as in experiments (Figs. 1c,e, 2). Occasionally, active states in the deafferented area occurred simultaneously with the intact network; however, in many cases, as in experimental observations (Fig. 4), these events were local, explaining the low amplitude of the simulated LFP (Fig. 8e). In this model, the generation of the active states was driven by intracortical mechanisms; however, active state synchronization depended on the thalamocortical projections and was severely diminished in the affected cortical areas after thalamic inactivation.

To describe more precisely the role of the thalamocortical projections in maintaining the normal pattern of the slow oscillation, we next evaluated the contribution of thalamocortical diffuse (matrix) versus specific (core) projections to the synchronization of the cortical active states. When the thalamocortical diffuse projections were fully dissected (Fig. 9a, left), transitions between active and silent states occurred independently among columns, as demonstrated by lower peak amplitude and longer time lag to the main peak of cross-correlation function (Fig. 9b,c). In contrast, removing only specific projections had no impact on the synchrony among columns $(p<$ 0.001 , two-sample $t$ test based on population of maximum crosscorrelation among columns; Fig. $9 a, b$, right). To further assess 
the impact of the thalamocortical input on the cortical synchronization of the slow waves, we varied the radius of thalamocortical connectivity in intact model and found that the intracortical synchrony increased as a function of the radius (Fig. 9d,e). This suggests that widespread thalamocortical projections play a critical role in the synchronization of the active cortical states across the entire cortical network.

We reproduced in the model the increase in the SD of the $V_{\mathrm{m}}$ fluctuations (Fig. 6) by adjusting the strength of longrange intracortical excitatory synapses. When thalamic inputs were blocked, the overall firing rate of the cortical neurons decreased due to lower levels of excitability. This matched the reduction in synaptic activity levels at the onset of active states recorded in vivo (Fig. 6e). Based on previous models of homeostatic changes in the neocortical network (Houweling et al., 2005; Volman et al., 2011a), the efficacy of excitatory (inhibitory) intracortical synapses was progressively upregulated (downregulated) until the mean firing rate reached the target value corresponding to the slow oscillation in the baseline model (Volman et al., 2011a). These processes led to a progressive recovery of the normal pattern of the sleep slow oscillation in the deafferented columns (Fig. 10a). The average frequency of active states increased with time (Fig. $10 c$ ) and the number of active state occurrence in affected columns was similar to the one observed in intact columns after the progressive upregulation of the intracortical excitatory drive to target value (Fig. 10d). The synchronization of activity across cortical columns was also recovered (Fig. 10e). However, when long-range intracortical synaptic connectivity was excluded from the upregulation of excitability, the frequency of active states recovered but synchronization was lost (Fig. 10b). These results suggest that the scaling of the longrange corticocortical synaptic connectivity could compensate for the loss of the thalamocortical feedback loop.

Synaptic scaling was suggested as a common mechanism of homeostatic plasticity (Turrigiano et al., 1998). However, other factors may contribute to the recovery of slow oscillation after the thalamic inactivation. This includes a homeostatic effect on neuromodulation, which can increase excitability by blocking $\mathrm{K}^{+}$ leak currents (McCormick, 1992), and on intrinsic conductances, which can affect the expression of intracellular excitatory and inhibitory conductances (Desai et al., 1999). To test these mechanisms, we implemented the scaling of various biophysical properties in the model. The results of these experiments for the intact and deafferented columns are shown in Figure 11. We first tested the downregulation of the $g_{\mathrm{KL}}$ in the dendritic compartment of all

C

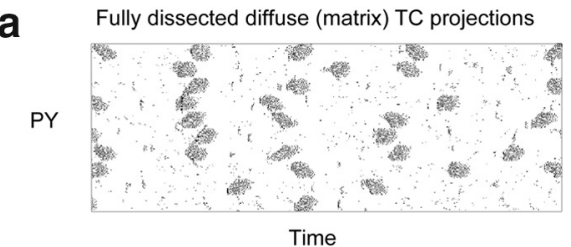

Fully dissected specific (core) TC projections
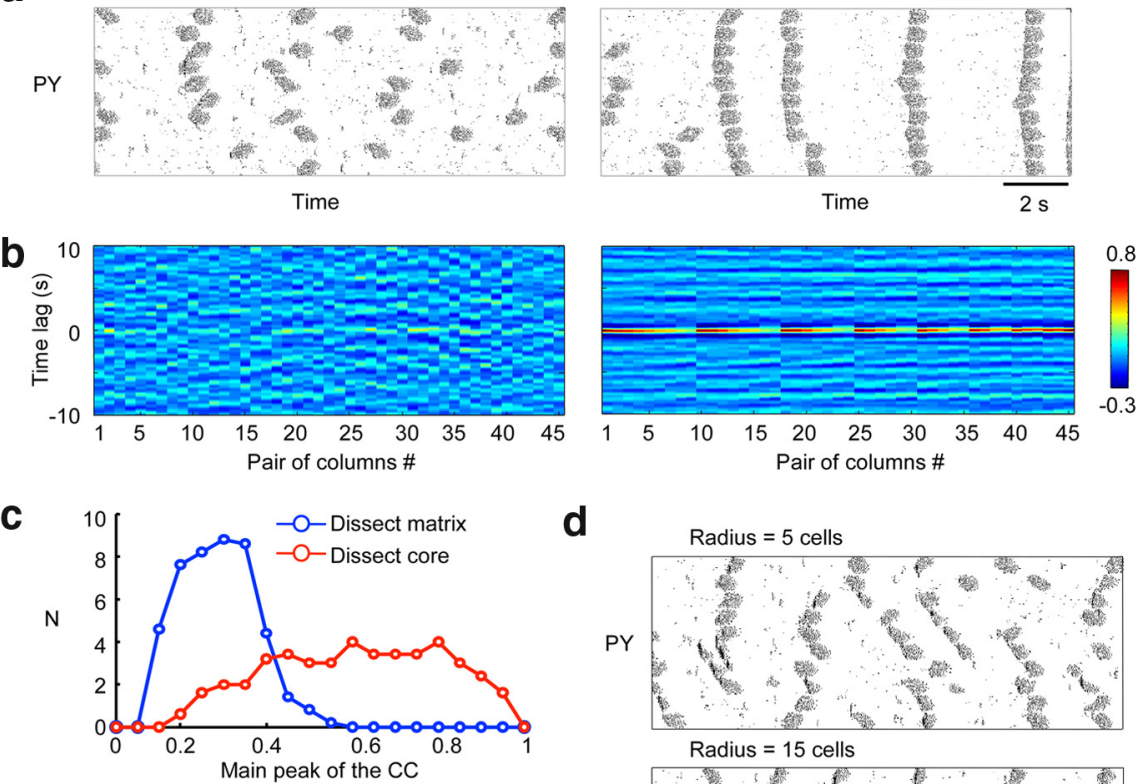

d
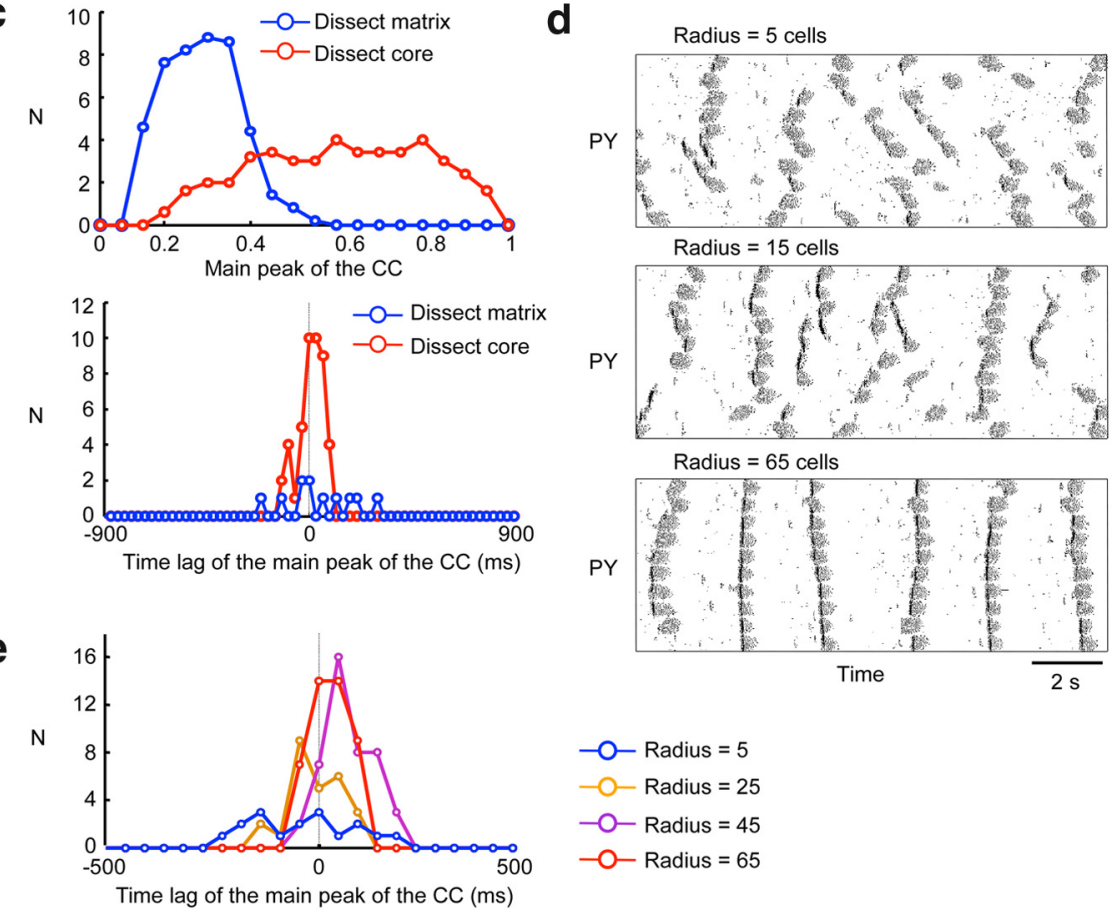

Radius $=65$ cells

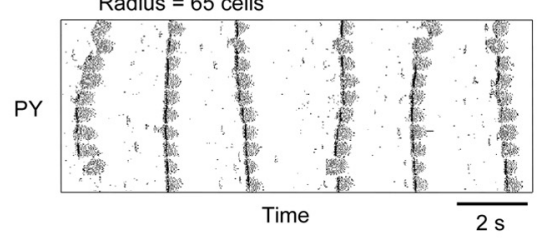

$-0-$ Radius $=5$
$-0-$ Radius $=25$
$-0-$ Radius $=45$
$-0-$ Radius $=65$

Figure 9. Impact of thalamocortical diffuse (matrix) versus specific (core) projections and the target radii on the synchronization of the slow oscillation. $\boldsymbol{a}$, Rastergrams of the layer IV PY neurons after full dissection of thalamocortical diffuse projections (left)

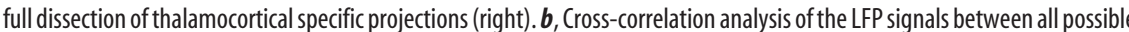
f the peak amplitude (top) and time lag to the main peak (bottom) of cross-correlation function for simulations with dissected iffuse (blue) and specific (red) projections. $\boldsymbol{d}$, Raster plots obtained from three different settings of the fan-out radius from the for all pairs of LFPs in different spatial locations plotted for various radii of thalamocortical projections. Broader distribution indicates less synchronous spatiotemporal activity.

pyramidal neurons (Fig. 11a). We found that this mechanism was sufficient to recover the frequency and with somewhat lower synchrony of slow oscillation (Fig. $11 b, c)$. In contrast, the scaling of the persistent $\mathrm{Na}^{+}$- and $\mathrm{Ca}^{2+}$-activated $\mathrm{K}^{+}$currents failed to recover normal slow oscillation (Fig. 11d). Although activity of pyramidal neurons increased along the simulation, it did not form a regular slow oscillation pattern; instead, it led to very long active states, which could last longer than $3 \mathrm{~s}$ (Fig. 11e). Furthermore, synchronization level across deafferented columns was not improved along the recovery process (Fig. 11f). Similar results were obtained with scaling of $g_{\mathrm{Na}}$ and $g_{\mathrm{Km}}$ or $g_{\text {GABA-A }}$ (Fig. $11 g$ ).

In sum, we found that scaling the strength of the excitatory connections between pyramidal neurons and the minis ampli- 
a
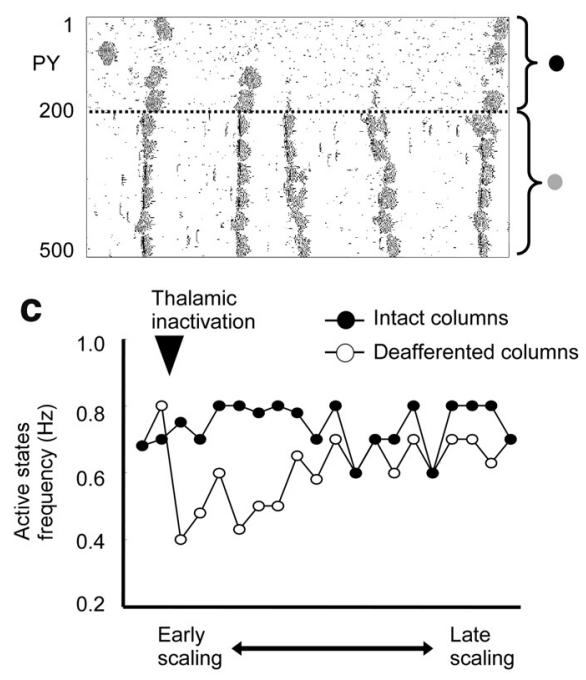

Thalamic inactivation (after scaling)

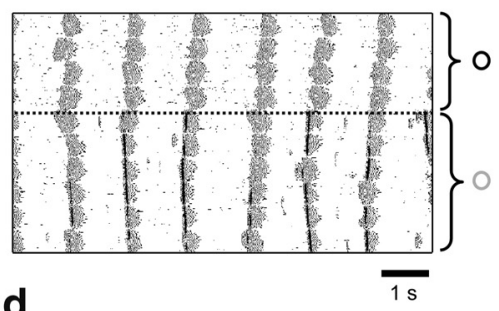

d

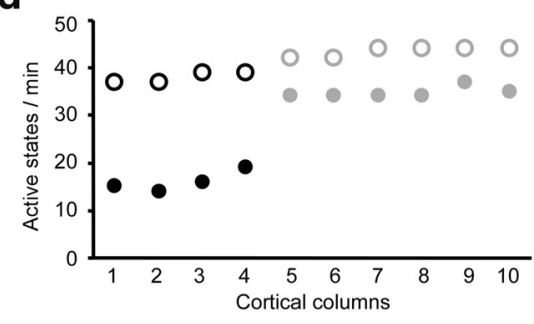

b

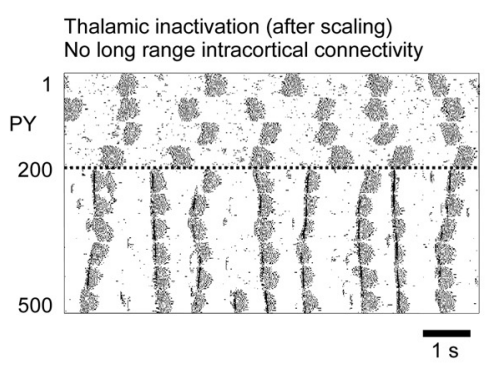

e

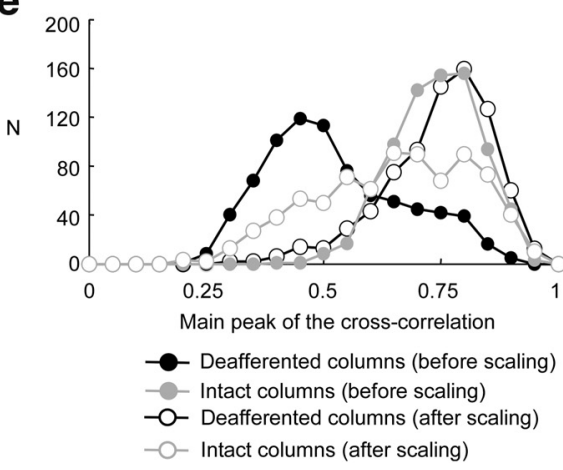

Figure 10. Modeling study of scaling the intracortical connectivity on the recovery of the neocortical slow oscillation. $\boldsymbol{a}$, Cortical slow oscillation after thalamic inactivation. Left, No synaptic scaling. Right, Pattern of cortical activity during late phase of synaptic scaling. Synaptic scaling was modeled as decrease of inhibition from IN to PY and increase of excitation and minis amplitude between PYs. $\boldsymbol{b}$, Network activity after synaptic scaling in the model without long-range intracortical connectivity. $\boldsymbol{c}$, Time course of active states frequency recovery in simulations with synaptic scaling. Arrowhead indicates the time of deafferentation. $\boldsymbol{d}$, Number of active states per minute after deafferentation without scaling (filled circle) or during the late phase of scaling (open circles). $e$, Distribution of main peak of the cross-correlation function between $V_{m}$ of neurons within deafferented columns (black) or intact columns (gray) without scaling (filled circles) or after scaling (open circles).

tude at these excitatory synapses (Figs. 10, $11 \mathrm{~g}$ ) was sufficient for the slow oscillation recovery. Furthermore, changing the passive intrinsic properties (such as leaking $\mathrm{K}^{+}$current) in pyramidal neurons was also able to mediate the recovery, likely because of the overall increase of excitability, although with lower levels of synchrony between neurons. Conversely, when scaling was applied to the active intrinsic conductances of the pyramidal neurons, the average firing rate of the network tended to increase, but the normal pattern of slow oscillation failed to recover.

\section{Discussion}

Using recordings from anesthetized and behaving cats, we found that the functional removal of thalamic inputs to the neocortex dramatically reduced the occurrence of active states of the slow oscillation. The remaining active states in the affected region were infrequent and local, explaining the low-amplitude LFP in that region. The slow oscillation started to recover $12 \mathrm{~h}$ after thalamic inactivation. Extending our investigation of this phenomenon to completely deafferented neocortical slabs, we observed a complete recovery of the slow oscillation within 2 weeks. This recovery of the slow oscillation occurred in parallel with an increase in spontaneous fluctuations of the membrane potential before the active states several hours after deafferentation, suggesting upregulation of excitatory synaptic drive. In a large-scale thalamocortical network model analysis, we replicated the disruption of the neocortical slow oscillation induced by removing the thalamic inputs to the cortex. We tested the effect of scaling various biophysical features of the model and found that the scaling of synaptic connectivity restored the frequency and synchrony of the slow oscillation. Upregulation of $g_{\mathrm{KL}}$ could restore the frequency of the slow oscillation, whereas the scaling of both fast and slow intrinsic $\mathrm{Na}^{+}$and $\mathrm{K}^{+}$conductances failed to recover the cortical slow oscillation. Collectively, our experimental and modeling results show that the normal pattern of the neocortical slow oscillation requires thalamic inputs, but suggests that there are cortical compensatory mechanisms to maintain the slow oscillation if thalamic input is damaged.

Thalamic and neocortical contribution to the slow oscillation The relative contribution of the neocortex and the thalamus in the expression of the slow oscillation has been debated over the last two decades. Our results confirm previous studies demonstrating that the neocortical network was sufficient to generate the slow waves (Steriade et al., 1993b; Timofeev and Steriade, 1996; Sanchez-Vives and McCormick, 2000; Timofeev et al., 2000; MacLean et al., 2005; Hinard et al., 2012). The other evidence suggests that the full expression of slow oscillation requires a contribution from the thalamus (Hughes et al., 2002; Doi et al., 2007; Crunelli and Hughes, 2010; David et al., 2013). Computer models revealed that the interaction between thalamic and cortical networks may be necessary for maintaining regular transitions between active and silent states (Destexhe, 2009). The present study clearly shows that, after the removal of thalamic inputs $(\sim 6 \%$ of excitatory synapses in the cortical network; Ahmed et al., 1994), the slow oscillation was replaced by local active states of much shorter duration that occurred irregularly and at a low rate. Similar results were obtained after complete isolation of a cortical area (slab), with regular active states having been replaced by irregular and infrequent events. We propose that the thalamocortical neurons: (1) participate in the generation of active states, (2) contribute to the normal duration of the active states by maintaining recurrent activity, and (3) play a major role in synchronizing the slow oscillation across cortical columns.

The thalamocortical network is tightly interconnected, which makes thalamocortical oscillations synchronous. Previ- 

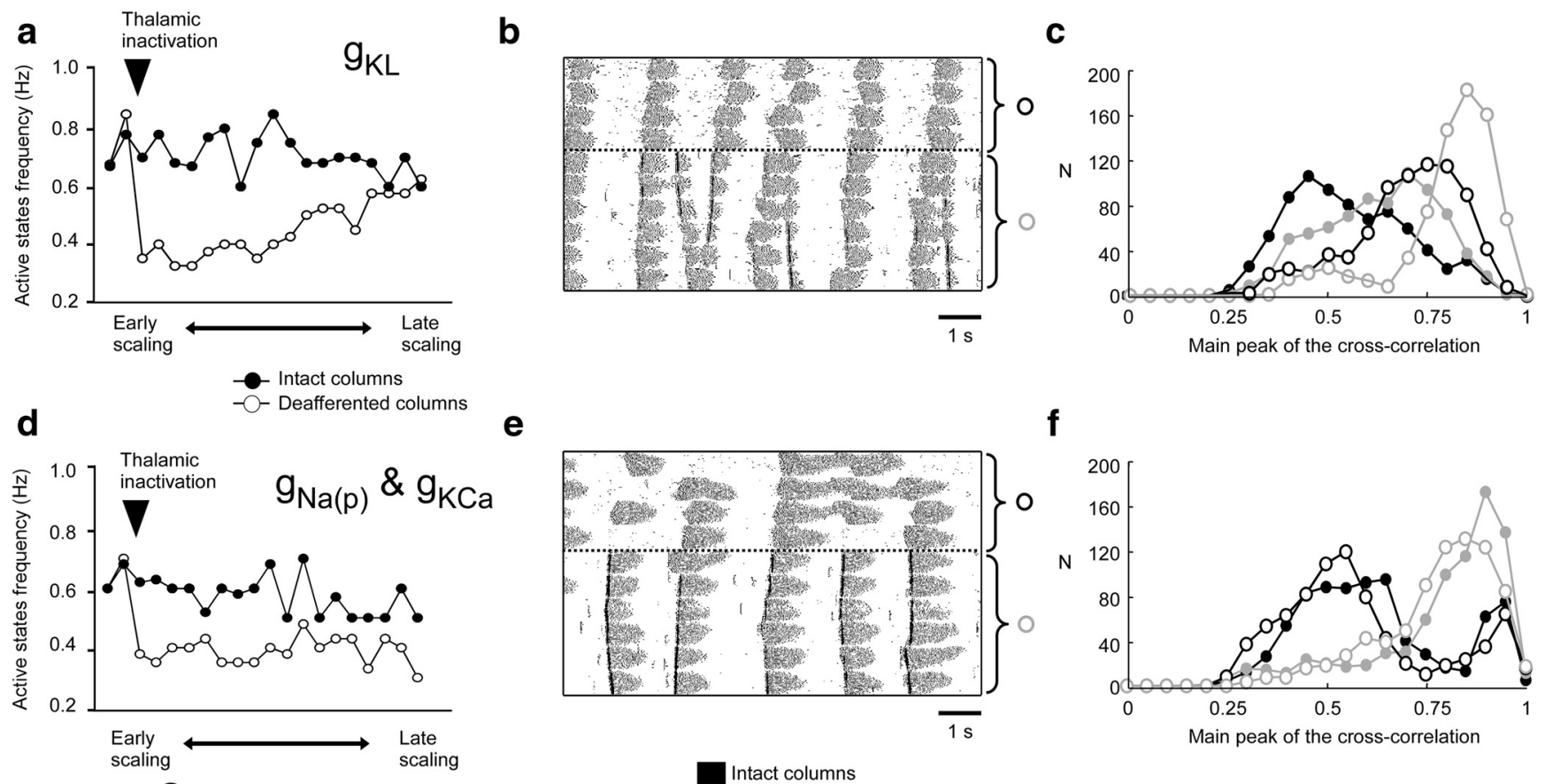

\section{e}

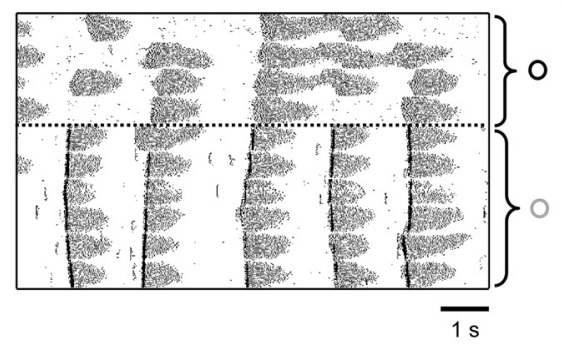

f

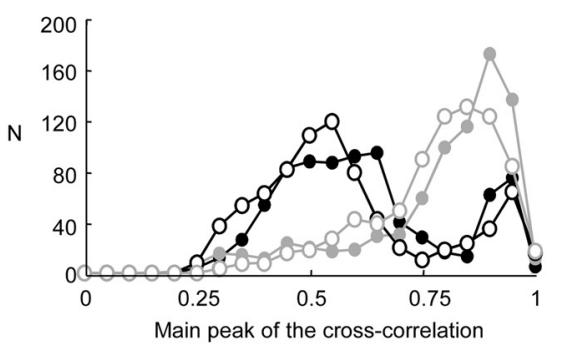

g
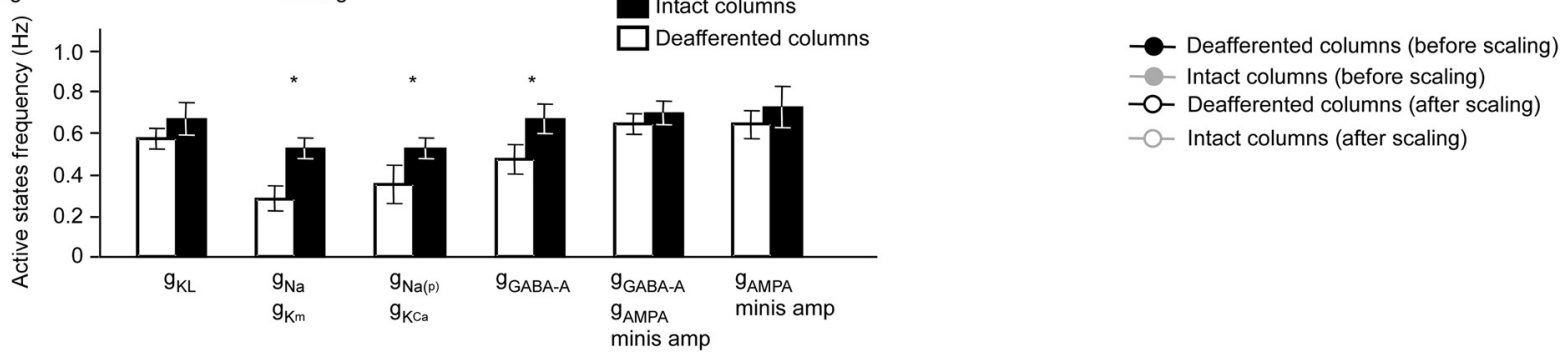

Figure 11. Role of different biophysical features in the recovery of the slow oscillation. $\boldsymbol{a}$, Scaling was modeled by adjusting the conductance of a leak potassium current $\left(g_{\mathrm{KL}}\right)$ in cortical neurons. Averaged active state frequency of intact columns (filled circle) and deafferented columns (open circle) along simulation. $\boldsymbol{b}$, Representative example of the network activity during the late phase of scaling. c, Distribution of the peaks of cross-correlation function between pyramidal neurons in deafferented (black) or intact (gray) columns during initial (filled circles) or late (open circles) phase of scaling. $\boldsymbol{d}-\boldsymbol{f}$, Similar to $\boldsymbol{a}-\boldsymbol{c}$, however, scaling was modeled by adjusting conductance of the slow intrinsic currents: persistent sodium current $\left(\boldsymbol{g}_{\text {Nap }}\right)$ and calcium-dependent potassium current $\left(g_{K C_{2}}\right) \cdot \boldsymbol{g}$, Frequency of active states in deafferented (open blocks) and intact (filled blocks) columns during the late phase of HSP. Six different settings of scaling are shown: (1) potassium leak current $\left(g_{\mathrm{KL}}\right)$ in PYs, (2) fast intrinsic currents $\left(g_{\mathrm{Na}}\right.$ and $\left.g_{\mathrm{Km}}\right)$ in PYs, (3) slow intrinsic current $\left(g_{\mathrm{Nap}}\right.$ and $\left.g_{\mathrm{KCa}}\right)$ in PYs, (4) fast synaptic inhibition $\left(g_{\mathrm{GABA}-\mathrm{A}}\right)$ from INs to PYs, (5) fast synaptic currents $\left(g_{\mathrm{GABA}-\mathrm{A}}\right.$ from INs to PYs, $g_{\text {AMPA }}$ and minis amplitude between PYs), and (6) fast synaptic excitation ( $g_{\text {AMPA }}$ and minis amplitude between PYs). Asterisk indicates experiments in which no recovery was found.

ous experimental (Contreras et al., 1996) and computational (Destexhe et al., 1998) studies have demonstrated that the removal of the cortex leads to the desynchronization of the spindle activity in the thalamus. Here, we show that thalamic inactivation desynchronizes the cortically generated slow oscillation without abolishing the generation of isolated cortical slow waves (Fig. 4). Importantly, several hours after deafferentation, the cortical plasticity processes reestablish the synchronization of slow waves (Fig. 3). In contrast, the recovery of a synchronous spindle activity with time was not demonstrated for thalamus in decorticated animals.

It was demonstrated previously in different species that, once slow waves are initiated in a specific location, they propagate to involve large cortical territories (Massimini et al., 2004; Volgushev et al., 2006; Mohajerani et al., 2010; Ruiz-Mejias et al., 2011). The fact that we observed isolated (local) cortical slow waves, which did not even propagate to neighboring regions, after the first hours after thalamic inactivation suggests that, in intact network, the thalamus plays a critical role in the generation of cortical propagation patterns. However, several hours after thalamic inactivation, the slow rhythm recovered in affected areas, indicating that, after a period of reorganization, the cortical network has functionally changed to promote the propagation of the slow waves.

In a large-scale model of the thalamocortical network with realistic network structure, we found that the dense local connectivity was sufficient to generate spontaneous active states, but widespread cortico-thalamo-cortical projections were required to ensure the propagation of the locally generated active states to the rest of the network. These results are in agreement with previous studies suggesting the role of the wide-spread (matrix) thalamocortical projections in the synchronization of cortical sleep spindle oscillations (Bonjean et al., 2012). When this connectivity was abolished to model the thalamic inactivation, the synchrony of active states was lost in the affected cortical areas. After a decrease in the overall level of activity, we found that the normal pattern of the slow oscillation could not be recovered by the scaling several $\mathrm{Na}^{+}$and $\mathrm{K}^{+}$conductances. However, an upregulation of excitatory synaptic conductances or a decrease in the potassium leak current recovered the slow oscillation, suggesting that these are the critical factors in the maintenance of cortical slow oscillation.

Unlike slow rhythms, the virtual abolition of fast rhythms in the neocortex did not recover over the investigated period 
of 36 h. Furthermore, the coincidence among neurons (based on fast rhythms grouped by the slow oscillation) was greatly diminished in the absence of thalamic inputs. These findings further suggest a role for the thalamus in the long-range synchrony of fast cortical activities. Although the synchronization of fast rhythms between thalamus and cortex was not investigated in detail, some studies have shown a coherence of these rhythms within the thalamocortical network (Steriade et al., 1996b; Castelo-Branco et al., 1998).

\section{Slow oscillation as the intrinsic property of the neocortex}

In the intact brain, the slow oscillation emerges as an alternation of active and silent states and occurs exclusively during slow-wave sleep (Steriade et al., 2001; Timofeev et al., 2001; Vyazovskiy et al., 2009). However, the patterns resembling the slow oscillation appear as a common feature of isolated cortical networks that develop with different time courses from initially "silent" cell primary cultures (Sun et al., 2010; Hinard et al., 2012), acute (Compte et al., 2008) and organotypic (Johnson and Buonomano, 2007) cortical slices, and neocortical slabs (Fig. 5). The main difference between the slow oscillation recorded in vivo during sleep or anesthesia and similar patterns recorded in isolated structures is the duration of silent states. Quantification of the duration of silent states in vivo demonstrate that they occupy $10-20 \%$ of the total sleep time (Chauvette et al., 2011), whereas available examples of recordings in acute, organotypic slices or cultures (Johnson and Buonomano, 2007; Compte et al., 2008; Sun et al., 2010; Hinard et al., 2012) show that the silent phase occupies $>80 \%$ of the time, which brings the overall frequency of slow oscillation to much lower values. In acute isolated neocortical slabs (Timofeev et al., 2000; Fig. 5a), the silent states are also long. However, field potential recordings from chronic slabs (Fig. $5 c$ ) demonstrate that, after a sufficient period of time, the duration of silent states becomes similar to the one recorded in the intact cortex. These observations suggest that some minimal level of connectivity is needed to generate slow waves with parameters found in the intact cortex. Such a minimal level of connectivity is absent in acute and organotypic slices.

We found that ongoing plastic changes in the intracortical network had begun the recovery of the slow oscillation pattern $12 \mathrm{~h}$ after surgery independently of thalamic inputs, thus matching the time course of homeostatic plasticity (Turrigiano et al., 1998; Turrigiano, 1999; Murthy et al., 2001; Desai et al., 2002). Experimental findings and a modeling approach further suggested that the homeostatic upregulation of the intracortical excitatory synapses was sufficient to restore the normal slow oscillation pattern (Fig. 10). In such conditions, long-range intracortical connectivity played a critical role in the synchronization of active states across the entire network.

The activities similar to the slow oscillation occur in the majority of neurons in the human brain even before birth (André et al., 2010; Moore et al., 2011). Although a role for the sleep slow oscillation in brain functions remains controversial, our results suggest that the slow oscillation is an intrinsic and a fundamental state of the thalamocortical system. This state is prominent during slow-wave sleep and we propose that it is maintained by intracortical plasticity mechanisms. A reduction in critical elements of the cortical network reduces the spontaneous slow-wave activity. However, it then recovers up to a normal sleep pattern after a period of time lasting from minutes to days. Conversely, after a sustained period of wakefulness, the sleep pressure increases (Achermann et al., 1993) and the local populations of cortical neurons start to display local sleep-like activities even if the whole brain is in a waking state (Vyazovskiy et al., 2011). Collectively, these results demonstrate that any factor leading to a reduction of the slow oscillation triggers plastic changes that bring back this intrinsic cortical rhythm.

\section{References}

Achermann P, Dijk DJ, Brunner DP, Borbély AA (1993) A model of human sleep homeostasis based on EEG slow-wave activity: Quantitative comparison of data and simulations. Brain Res Bull 31:97-113. CrossRef Medline

Ahmed B, Anderson JC, Douglas RJ, Martin KA, Nelson JC (1994) Polyneuronal innervation of spiny stellate neurons in cat visual cortex. J Comp Neurol 341:39-49. CrossRef Medline

Aladjalova NA (1957) Infra-slow rhythmic oscillations of the steady potential of the cerebral cortex. Nature 179:957-959. Medline

André M, Lamblin MD, d'Allest AM, Curzi-Dascalova L, MoussalliSalefranque F, S Nguyen The T, Vecchierini-Blineau MF, Wallois F, Walls-Esquivel E, Plouin P (2010) Electroencephalography in premature and full-term infants: developmental features and glossary. Neurophysiol Clin 40:59-124. CrossRef Medline

Bazhenov M, Timofeev I, Steriade M, Sejnowski TJ (1998) Cellular and network models for intrathalamic augmenting responses during 10-hz stimulation. J Neurophysiol 79:2730-2748. Medline

Bazhenov M, Timofeev I, Steriade M, Sejnowski TJ (2002) Model of thalamocortical slow-wave sleep oscillations and transitions to activated states. J Neurosci 22:8691-8704. Medline

Blake H, Gerard RW (1937) Brain potentials during sleep. Am J Physiol 119:692-703.

Bonjean M, Baker T, Bazhenov M, Cash S, Halgren E, Sejnowski T (2012) Interactions between core and matrix thalamocortical projections in human sleep spindle synchronization. J Neurosci 32:5250-5263. CrossRef Medline

Castelo-Branco M, Neuenschwander S, Singer W (1998) Synchronization of visual responses between the cortex, lateral geniculate nucleus, and retina in the anesthetized cat. J Neurosci 18:6395-6410. Medline

Chauvette S, Volgushev M, Timofeev I (2010) Origin of active states in local neocortical networks during slow sleep oscillation. Cereb Cortex 20: 2660-2674. CrossRef Medline

Chauvette S, Crochet S, Volgushev M, Timofeev I (2011) Properties of slow oscillation during slow-wave sleep and anesthesia in cats. J Neurosci 31: 14998-15008. CrossRef Medline

Chauvette S, Seigneur J, Timofeev I (2012) Sleep oscillations in the thalamocortical system induce long-term neuronal plasticity. Neuron 75:11051113. CrossRef Medline

Chen JY, Chauvette S, Skorheim S, Timofeev I, Bazhenov M (2012) Interneuron-mediated inhibition synchronizes neuronal activity during slow oscillation. J Physiol 590:3987-4010. CrossRef Medline

Compte A, Sanchez-Vives MV, McCormick DA, Wang XJ (2003) Cellular and network mechanisms of slow oscillatory activity $(<1 \mathrm{hz})$ and wave propagations in a cortical network model. J Neurophysiol 89:2707-2725. CrossRef Medline

Compte A, Reig R, Descalzo VF, Harvey MA, Puccini GD, Sanchez-Vives MV (2008) Spontaneous high-frequency $(10-80 \mathrm{hz})$ oscillations during up states in the cerebral cortex in vitro. J Neurosci 28:13828-13844. CrossRef Medline

Contreras D, Steriade M (1995) Cellular basis of eeg slow rhythms: a study of dynamic corticothalamic relationships. J Neurosci 15:604-622. Medline

Contreras D, Destexhe A, Sejnowski TJ, Steriade M (1996) Control of spatiotemporal coherence of a thalamic oscillation by corticothalamic feedback. Science 274:771-774. CrossRef Medline

Crunelli V, Hughes SW (2010) The slow $(<1 \mathrm{hz})$ rhythm of non-rem sleep: a dialogue between three cardinal oscillators. Nat Neurosci 13:9-17. CrossRef Medline

Csercsa R, Dombovári B, Fabó D, Wittner L, Eross L, Entz L, Sólyom A, Rásonyi G, Szucs A, Kelemen A, Jakus R, Juhos V, Grand L, Magony A, Halász P, Freund TF, Maglóczky Z, Cash SS, Papp L, Karmos G, et al. (2010) Laminar analysis of slow wave activity in humans. Brain 133: 2814-2829. CrossRef Medline

David F, Schmiedt JT, Taylor HL, Orban G, Di Giovanni G, Uebele VN, 
Renger JJ, Lambert RC, Leresche N, Crunelli V (2013) Essential thalamic contribution to slow waves of natural sleep. J Neurosci 33:1959919610. CrossRef Medline

Desai NS, Rutherford LC, Turrigiano GG (1999) Plasticity in the intrinsic excitability of cortical pyramidal neurons. Nat Neurosci 2:515-520. CrossRef Medline

Desai NS, Cudmore RH, Nelson SB, Turrigiano GG (2002) Critical periods for experience-dependent synaptic scaling in visual cortex. Nat Neurosci 5:783-789. CrossRef Medline

Destexhe A (2009) Self-sustained asynchronous irregular states and updown states in thalamic, cortical and thalamocortical networks of nonlinear integrate-and-fire neurons. J Comput Neurosci 27:493-506. CrossRef Medline

Destexhe A, Sejnowski T (2001) Thalamocortical assemblies: How ion channels, single neurons and large-scale networks organize sleep oscillations. Oxford: OUP.

Destexhe A, Contreras D, Steriade M (1998) Mechanisms underlying the synchronizing action of corticothalamic feedback through inhibition of thalamic relay cells. J Neurophysiol 79:999-1016. Medline

Dickson CT, Biella G, de Curtis M (2003) Slow periodic events and their transition to gamma oscillations in the entorhinal cortex of the isolated guinea pig brain. J Neurophysiol 90:39-46. CrossRef Medline

Diekelmann S, Born J (2010) The memory function of sleep. Nat Rev Neurosci 11:114-126. CrossRef Medline

Doi A, Mizuno M, Katafuchi T, Furue H, Koga K, Yoshimura M (2007) Slow oscillation of membrane currents mediated by glutamatergic inputs of rat somatosensory cortical neurons: In vivo patch-clamp analysis. Eur J Neurosci 26:2565-2575. CrossRef Medline

Draguhn A, Traub RD, Schmitz D, Jefferys JG (1998) Electrical coupling underlies high-frequency oscillations in the hippocampus in vitro. Nature 394:189-192. CrossRef Medline

Fröhlich F, Bazhenov M, Sejnowski TJ (2008) Pathological effect of homeostatic synaptic scaling on network dynamics in diseases of the cortex. J Neurosci 28:1709-1720. CrossRef Medline

Gais S, Plihal W, Wagner U, Born J (2000) Early sleep triggers memory for early visual discrimination skills. Nat Neurosci 3:1335-1339. CrossRef Medline

Hasenstaub A, Shu Y, Haider B, Kraushaar U, Duque A, McCormick DA (2005) Inhibitory postsynaptic potentials carry synchronized frequency information in active cortical networks. Neuron 47:423-435. CrossRef Medline

Hinard V, Mikhail C, Pradervand S, Curie T, Houtkooper RH, Auwerx J, Franken P, Tafti M (2012) Key electrophysiological, molecular, and metabolic signatures of sleep and wakefulness revealed in primary cortical cultures. J Neurosci 32:12506-12517. CrossRef Medline

Houweling AR, Bazhenov M, Timofeev I, Steriade M, Sejnowski TJ (2005) Homeostatic synaptic plasticity can explain post-traumatic epileptogenesis in chronically isolated neocortex. Cereb Cortex 15:834-845. CrossRef Medline

Huber R, Ghilardi MF, Massimini M, Tononi G (2004) Local sleep and learning. Nature 430:78-81. CrossRef Medline

Hughes SW, Cope DW, Blethyn KL, Crunelli V (2002) Cellular mechanisms of the slow $(<1 \mathrm{hz})$ oscillation in thalamocortical neurons in vitro. Neuron 33:947-958. CrossRef Medline

Johnson HA, Buonomano DV (2007) Development and plasticity of spontaneous activity and up states in cortical organotypic slices. J Neurosci 27:5915-5925. CrossRef Medline

MacLean JN, Watson BO, Aaron GB, Yuste R (2005) Internal dynamics determine the cortical response to thalamic stimulation. Neuron 48:811823. CrossRef Medline

Mainen ZF, Sejnowski TJ (1996) Influence of dendritic structure on firing pattern in model neocortical neurons. Nature 382:363-366. CrossRef Medline

Maquet P (2001) The role of sleep in learning and memory. Science 294: 1048-1052. CrossRef Medline

Marshall L, Helgadóttir H, Mölle M, Born J (2006) Boosting slow oscillations during sleep potentiates memory. Nature 444:610-613. CrossRef Medline

Massimini M, Huber R, Ferrarelli F, Hill S, Tononi G (2004) The sleep slow oscillation as a traveling wave. J Neurosci 24:6862-6870. CrossRef Medline

McCormick DA (1992) Neurotransmitter actions in the thalamus and cere- bral cortex and their role in neuromodulation of thalamocortical activity. Prog Neurobiol 39:337-388. CrossRef Medline

Mohajerani MH, McVea DA, Fingas M, Murphy TH (2010) Mirrored bilateral slow-wave cortical activity within local circuits revealed by fast bihemispheric voltage-sensitive dye imaging in anesthetized and awake mice. J Neurosci 30:3745-3751. CrossRef Medline

Moore AR, Zhou WL, Jakovcevski I, Zecevic N, Antic SD (2011) Spontaneous electrical activity in the human fetal cortex in vitro. J Neurosci 31: 2391-2398. CrossRef Medline

Mukovski M, Chauvette S, Timofeev I, Volgushev M (2007) Detection of active and silent states in neocortical neurons from the field potential signal during slow-wave sleep. Cereb Cortex 17:400-414. CrossRef Medline

Murthy VN, Schikorski T, Stevens CF, Zhu Y (2001) Inactivity produces increases in neurotransmitter release and synapse size. Neuron 32:673682. CrossRef Medline

Reinoso-Suarez F (1961) Topographischer hirnatlas der katze, fur experimental-physiologische untersuchungen. Darmstadt, Germany: Merck.

Rudolph M, Pospischil M, Timofeev I, Destexhe A (2007) Inhibition determines membrane potential dynamics and controls action potential generation in awake and sleeping cat cortex. J Neurosci 27:5280-5290. CrossRef Medline

Ruiz-Mejias M, Ciria-Suarez L, Mattia M, Sanchez-Vives MV (2011) Slow and fast rhythms generated in the cerebral cortex of the anesthetized mouse. J Neurophysiol 106:2910-2921. CrossRef Medline

Sanchez-Vives MV, McCormick DA (2000) Cellular and network mechanisms of rhythmic recurrent activity in neocortex. Nat Neurosci 3:10271034. CrossRef Medline

Shu Y, Hasenstaub A, McCormick DA (2003) Turning on and off recurrent balanced cortical activity. Nature 423:288-293. CrossRef Medline

Siegel JM (2005) Clues to the functions of mammalian sleep. Nature 437: 1264-1271. CrossRef Medline

Steriade M (2006) Grouping of brain rhythms in corticothalamic systems. Neuroscience 137:1087-1106. CrossRef Medline

Steriade M, Timofeev I (2003) Neuronal plasticity in thalamocortical networks during sleep and waking oscillations. Neuron 37:563-576. CrossRef Medline

Steriade M, Nuñez A, Amzica F (1993a) Intracellular analysis of relations between the slow $(<1 \mathrm{hz})$ neocortical oscillations and other sleep rhythms of electroencephalogram. J Neurosci 13:3266-3283. Medline

Steriade M, Nuñez A, Amzica F (1993b) A novel slow ( $<1 \mathrm{hz}$ ) oscillation of neocortical neurons in vivo: Depolarizing and hyperpolarizing components. J Neurosci 13:3252-3265. Medline

Steriade M, McCormick DA, Sejnowski TJ (1993c) Thalamocortical oscillations in the sleeping and aroused brain. Science 262:679-685. CrossRef Medline

Steriade M, Amzica F, Contreras D (1996a) Synchronization of fast (30-40 hz) spontaneous cortical rhythms during brain activation. J Neurosci 16:392-417. Medline

Steriade M, Contreras D, Amzica F, Timofeev I (1996b) Synchronization of fast $(30-40 \mathrm{hz})$ spontaneous oscillations in intrathalamic and thalamocortical networks. J Neurosci 16:2788-2808. Medline

Steriade M, Timofeev I, Grenier F (2001) Natural waking and sleep states: A view from inside neocortical neurons. J Neurophysiol 85:1969-1985. Medline

Stevens CF (1993) Quantal release of neurotransmitter and long-term potentiation. Cell 72:55-63. CrossRef Medline

Stickgold R, James L, Hobson JA (2000) Visual discrimination learning requires sleep after training. Nat Neurosci 3:1237-1238. CrossRef Medline

Sun JJ, Kilb W, Luhmann HJ (2010) Self-organization of repetitive spike patterns in developing neuronal networks in vitro. Eur J Neurosci 32: 1289-1299. CrossRef Medline

Thomson AM, Bannister AP (2003) Interlaminar connections in the neocortex. Cereb Cortex 13:5-14. CrossRef Medline

Timofeev I (2011) Neuronal plasticity and thalamocortical sleep and waking oscillations. In: Progress in brain research (Someren EJWV, Werf YDVD, Roelfsema PR, Mansvelder HD, Lopes Da Silva F, eds), pp 121144. Amsterdam: Elsevier.

Timofeev I, Steriade M (1996) Low-frequency rhythms in the thalamus of intact-cortex and decorticated cats. J Neurophysiol 76:4152-4168. Medline 
Timofeev I, Grenier F, Bazhenov M, Sejnowski TJ, Steriade M (2000) Origin of slow cortical oscillations in deafferented cortical slabs. Cereb Cortex 10:1185-1199. CrossRef Medline

Timofeev I, Grenier F, Steriade M (2001) Disfacilitation and active inhibition in the neocortex during the natural sleep-wake cycle: an intracellular study. Proc Natl Acad Sci U S A 98:1924-1929. CrossRef Medline

Tononi G, Cirelli C (2006) Sleep function and synaptic homeostasis. Sleep Med Rev 10:49-62. CrossRef Medline

Turrigiano GG (1999) Homeostatic plasticity in neuronal networks: The more things change, the more they stay the same. Trends Neurosci 22:221-227. CrossRef Medline

Turrigiano GG, Leslie KR, Desai NS, Rutherford LC, Nelson SB (1998) Activity-dependent scaling of quantal amplitude in neocortical neurons. Nature 391:892-896. CrossRef Medline

Volgushev M, Chauvette S, Mukovski M, Timofeev I (2006) Precise long-range synchronization of activity and silence in neocortical neu- rons during slow-wave sleep. J Neurosci 26:5665-5672. CrossRef Medline

Volman V, Bazhenov M, Sejnowski TJ (2011a) Pattern of trauma determines the threshold for epileptic activity in a model of cortical deafferentation. Proc Natl Acad Sci U S A 108:15402-15407. CrossRef Medline

Volman V, Sejnowski TJ, Bazhenov M (2011b) Topological basis of epileptogenesis in a model of severe cortical trauma. J Neurophysiol 106:19331942. CrossRef Medline

Vyazovskiy VV, Olcese U, Lazimy YM, Faraguna U, Esser SK, Williams JC, Cirelli C, Tononi G (2009) Cortical firing and sleep homeostasis. Neuron 63:865-878. CrossRef Medline

Vyazovskiy VV, Olcese U, Hanlon EC, Nir Y, Cirelli C, Tononi G (2011) Local sleep in awake rats. Nature 472:443-447. CrossRef Medline

Whittington MA, Traub RD, Jefferys JG (1995) Synchronized oscillations in interneuron networks driven by metabotropic glutamate receptor activation. Nature 373:612-615. CrossRef Medline 